OPEN ACCESS

Edited by:

Lucia Lopalco,

San Raffaele Hospital (IRCCS), Italy

Reviewed by:

Joseph Icenogle,

Centers for Disease Control and

Prevention (CDC), United States

Sarah Londrigan,

The University of Melbourne, Australia

Yongming Sang,

Tennessee State University,

United States

*Correspondence:

Sunna Hauschildt shaus@rz.uni-leipzig.de

${ }^{t}$ These authors have contributed equally to this work

Specialty section:

This article was submitted to

Viral Immunology,

a section of the journal

Frontiers in Immunology

Received: 08 September 2021 Accepted: 22 November 2021 Published: 16 December 2021

Citation:

Schilling E, Grahnert A, Pfeiffer L, Koehl U, Claus $C$ and Hauschildt $S$ (2021) The Impact of Rubella Virus

Infection on a Secondary

Inflammatory Response in

Polarized Human Macrophages.

Front. Immunol. 12:772595.

doi: 10.3389/fimmu.2021.772595

\section{The Impact of Rubella Virus Infection on a Secondary Inflammatory Response in Polarized Human Macrophages}

\author{
Erik Schilling ${ }^{1}$, Anja Grahnert ${ }^{1}$, Lukas Pfeiffer ${ }^{2}$, Ulrike Koehl ${ }^{1,3,4}$, Claudia Claus ${ }^{2 \dagger}$ \\ and Sunna Hauschildt ${ }^{5 * t}$
}

\begin{abstract}
${ }^{1}$ Institute of Clinical Immunology, Medical Faculty, University of Leipzig, Leipzig, Germany, ${ }^{2}$ Institute of Medical Microbiology and Virology, Medical Faculty, University of Leipzig, Leipzig, Germany, ${ }^{3}$ Fraunhofer Institute for Cellular Therapeutics and Immunology, Leipzig, Germany, ${ }^{4}$ Institute for Cellular Therapeutics, Hannover Medical School, Hannover, Germany, 5 Institute of Biology, University of Leipzig, Leipzig, Germany
\end{abstract}

Macrophages (M $\Phi)$ are known to exhibit distinct responses to viral and bacterial infection, but how they react when exposed to the pathogens in succession is less well understood. Accordingly, we determined the effect of a rubella virus (RV)-induced infection followed by an LPS-induced challenge on cytokine production, signal transduction and metabolic pathways in human GM (M1-like)- and M (M2-like)-M $\Phi$. We found that infection of both subsets with RV resulted in a low TNF- $\alpha$ and a high interferon (IFN, type I and type III) release whereby M-M $\Phi$ produced far more IFNs than GM-M $\Phi$. Thus, TNF- $\alpha$ production in contrast to IFN production is not a dominant feature of RV infection in these cells. Upon addition of LPS to RV-infected M $\Phi$ compared to the addition of LPS to the uninfected cells the TNF- $\alpha$ response only slightly increased, whereas the IFN-response of both subtypes was greatly enhanced. The subset specific cytokine expression pattern remained unchanged under these assay conditions. The priming effect of RV was also observed when replacing RV by IFN- $\beta$ one putative priming stimulus induced by RV. Small amounts of IFN- $\beta$ were sufficient for phosphorylation of Stat1 and to induce IFN-production in response to LPS. Analysis of signal transduction pathways activated by successive exposure of $M \Phi$ to RV and LPS revealed an increased phosphorylation of NFKB (M$M \Phi$ ), but different to uninfected $M \Phi$ a reduced phosphorylation of ERK1/2 (both subtypes). Furthermore, metabolic pathways were affected; the LPS-induced increase in glycolysis was dampened in both subtypes after RV infection. In conclusion, we show that RV infection and exogenously added IFN- $\beta$ can prime $M \Phi$ to produce high amounts of IFNs in response to LPS and that changes in glycolysis and signal transduction are associated with the priming effect. These findings will help to understand to what extent $M \Phi$ defense to viral infection is modulated by a following exposure to a bacterial infection. 


\section{INTRODUCTION}

Macrophages (M $)$ are a vital part of the innate immune response. They comprise different activation states that have been generally categorized into two broad but distinct subsets termed M1-MФ (classically activated) and M2-M $\Phi$ (alternatively activated). While M1-M $\Phi$ triggered by interferon (IFN)- $\gamma$ in combination with Tolllike receptor (TLR) agonist lipopolysaccharide (LPS) promote proinflammatory and tumoricidal properties, M2-M $\Phi$ generated in response to IL- 4 and IL-13 show anti-inflammatory and protumoral properties and serve key roles in wound healing and tissue repair. These classes are generally accepted to be at the opposite extremes of a spectrum of intermediate phenotypes (1).

However, next to the generation of M1 and M2 phenotypes other models use growth-factors namely GM- and M-CSF to generate pro- and anti-inflammatory $M \Phi$, respectively. These factors reflect in vivo conditions as M-CSF has been implicated in the steady state control of macrophage development whereas levels of GM-CSF are elevated during inflammatory reactions. As M $\Phi$ developed in the presence of CSFs do not exactly mirror those of the activated M1- and M2-M $\Phi$ we will refer to the two subsets used here as GM- and M-M $\Phi$, respectively (2).

Besides tissue development, homeostasis and tissue repair MФ play a crucial role in immunity to pathogens including both bacteria and viruses. They respond to these pathogens by producing a variety of mediators including cytokines like TNF- $\alpha$ and IFNs. When exposed to LPS TNF- $\alpha$ is mainly released by pro-inflammatory $M \Phi$, while anti-inflammatory $M \Phi$ only produce low levels of this cytokine, but secrete instead high amounts of IFNs (2).

In contrast to the well-defined LPS-induced cytokine response of the two $M \Phi$ subsets, the role of the different phenotypes in mediating TNF- $\alpha$ and IFN release upon viral infection has been less extensively studied.

As reviewed lately by Nikitina et al., monocytes and $M \Phi$, cells with an extended life span and access to tissues, can be subverted by multiple viruses from different families (3). These viruses include RNA viruses such as Chikungunya virus, which persists in $M \Phi$ (4), as well as DNA viruses such as human cytomegalovirus, which was shown to replicate in $\mathrm{M} \Phi$ up to 16 weeks after infection (5). The reproductive cycle of retroviruses including human immunodeficiency virus (HIV) involves latency and chronic replication in monocytes and M $\Phi$ as reviewed by Le Douce et al. (6). Several lines of evidence support the relevance of $M \Phi$ for the pathogenesis of the single-stranded, plus-sense RNA virus rubella virus $(\mathrm{RV})$. RV is transmitted via aerosols and after initial replication in the respiratory tract spreads to local lymphnodes. This leads to lymphadenopathy as one of the early detectable symptoms of rubella infection (7). It is very likely that MФ serve as targets of RV within the lymphnodes and that, as suggested by van der Logt et al. (8), the virus replicates within these cells. Additionally, viral antigen was detected in human $\mathrm{M} \Phi$ in clinical samples. The antigen was found in alveolar M $\Phi$ in tissue samples of children born with fatal congenital rubella (9) and in M2-MФ present in RV-associated cutaneous granulomas of patients with primary immunodeficiency disorders (PID) (10).

It is especially noteworthy, that RV can replicate in both human $\mathrm{M} \Phi$ types (11) thus allowing a direct comparison of virus infection-associated changes in the two subsets.
In view of the still ill-defined role of human $M \Phi$ in RV dissemination in the body and their impact on the associated pathogenesis, we here asked to what extend RV affects immune functions and metabolic profile of MФ and how RV alters their response when exposed to LPS as a second stimulus. This experimental approach will deepen our understanding into the competence of $M \Phi$ to respond to RV and into RV-induced reactions, that become apparent after a coinfection.

We found that infection of GM- and M-M $\Phi$ with RV alone or followed by a challenge with LPS alters their cytokine release, metabolic activity and signal transduction pathways. The here presented data underline the relevance of dissecting the cellular responses to the coinfection to better understand the RV infection-induced effects on the innate immune system.

\section{MATERIAL AND METHODS}

Unless otherwise indicated, materials used in this study were from the following manufacturers: Sigma-Aldrich (Taufkirchen, Germany): fetal calf serum (FCS), LPS from E. coli (serotype 055:B5); Seromed Biochrom KG (Berlin, Germany): penicillin, streptomycin; GE Healthcare (Little Chalfont, Buckinghamshire, UK): RPMI 1640 (with L-glutamine, 25 mM HEPES and phenol red), Ficoll-Paque ${ }^{\mathrm{TM}}$ Plus.

Recombinant human IFN- $\beta$ was purchased from Peprotech (Hamburg, Germany) and the monoclonal antibody against RV capsid (C) protein (clon 2-36) from Meridian Life Science, Inc. (Memphis, TN, USA). Material and reagents for measuring cellular metabolism by extracellular flux analysis with the Seahorse technology were purchased from Agilent Seahorse Technologies (Santa Clara, CA, USA).

\section{Cell Separation and Cell Culture}

Buffy coats of healthy donors were acquired from the blood service (Institute of Transfusion Medicine University Hospital Leipzig; ethics license 272-12-13082012). Human peripheral blood mononuclear cells were obtained from buffy coats by Ficoll-Paque Plus density centrifugation. After washing with PBS containing $0.3 \mathrm{mM}$ EDTA, monocytes were isolated by counter-flow elutriation using the JE-5.0 elutriation system (Beckman Coulter, Brea, CA, USA), as described previously (12).

Monocytes $\left(5 \times 10^{5} / \mathrm{ml}\right)$ with a purity of at least $90 \%$, as assessed by flow cytometry using anti-CD14-APC Ab (M5E2, BioLegend, San Diego, CA, USA) were suspended in RPMI 1640 medium supplemented with $10 \%(\mathrm{v} / \mathrm{v})$ FCS, $100 \mathrm{U} / \mathrm{ml}$ penicillin and 100 $\mathrm{mg} / \mathrm{ml}$ streptomycin and differentiated with $500 \mathrm{IU} / \mathrm{ml}$ GM-CSF (Leukine, sargramostim) to GM-M $\Phi$ or $50 \mathrm{ng} / \mathrm{ml} \mathrm{M-CSF} \mathrm{(R \& D}$ Systems, Minneapolis, MO, USA) to M-M $\Phi$ at $37^{\circ} \mathrm{C}$ and $5 \% \mathrm{CO}_{2}$ in teflon bags (Zell-Kontakt, Nörte-Hardenberg, Germany; fluorinated ethylene propylene foil, $50 \mu \mathrm{m}$, hydrophobic). After seven days, MФ $\left(5 \times 10^{5} / \mathrm{ml}\right)$ were suspended in RPMI 1640 medium supplemented with $10 \%(\mathrm{v} / \mathrm{v})$ FCS, $100 \mathrm{U} / \mathrm{ml}$ penicillin and $100 \mathrm{mg} / \mathrm{ml}$ streptomycin and incubated for $2 \mathrm{~h}$ in cell culture plates before starting experiments. Flow cytometry analysis of M $\Phi$ cell surface markers was performed as described previously (13), using direct dye-labelled antibodies anti-CD14-APC (M5E2, 
BioLegend), anti-CD40-PerCp (Elabscience Biotechnology, Houston, TX, USA), anti-CD80-PE (L307, BD Pharmingen, San Jose, CA, USA) and the unlabelled antibody anti-CD163 (GHI/61 BD Pharmingen) in combination with a FITC-labelled goat antimouse secondary antibody.

\section{Virus Infections}

Virus infection was carried out as previously described (11). Stock virus preparations of the low-passaged (up to passage 10) clinical isolate RVi/Wuerzburg.DEU/47.11_12-00009 (Wb-12) were prepared and titered by standard plaque assay on Vero cells (green monkey kidney epithelial cell line, ATCC CCL-81). Vero cells were cultured in Dulbecco's modified Eagle's medium (DMEM; Thermo Fisher Scientific) with 10\% (v/v) FCS. Human M $\Phi$ were infected with RV (approved by the ethics committee at the Medical Faculty of the University of Leipzig; ethics license 001/19-ek) at a multiplicity of infection (MOI) of 1.5. Cells that were not infected (mock) or treated with RV inactivated by exposure to UV-light $\left(750,000 \mu \mathrm{J} / \mathrm{cm}^{2}\right.$ (UVStratalinker 2000, Stratagene)) (UV-RV) served as controls. UV-RV was applied at the same MOI as RV. Before infection culture media were discarded and RV or the respective controls (mock and UV-RV) were added. After $2 \mathrm{~h}$ of incubation the media were removed, MФ were washed with PBS and suspended in fresh culture media.

\section{Immunofluorescence Microscopy}

The immunofluorescence analysis of RV-infected M $\Phi$ was performed as described previously (14). Briefly, MФ were cultivated on glass slides, washed at 24 hours post-infection (hpi) with PBS, and fixed with $2 \%(\mathrm{w} / \mathrm{v})$ paraformaldehyde (PFA) in PBS for 15 min. After fixation, cells were washed with PBS and permeabilized with $0.3 \%$ Triton X-100 (v/v) in PBS at $37^{\circ} \mathrm{C}$ for $30 \mathrm{~min}$ followed by blocking with $0.3 \%$ Triton $\mathrm{X}-100$ $(\mathrm{v} / \mathrm{v})$ and $5 \%$ normal goat serum (v/v) in $\mathrm{PBS}$ for $30 \mathrm{~min}$ at $37^{\circ} \mathrm{C}$ in a humidified chamber. Thereafter cells were incubated with primary mouse monoclonal antibody to rubella capsid protein (clone 2-36; 1:200 dilution; Meridian Life Science Inc, Saco, ME USA) for $60 \mathrm{~min}$ at $37^{\circ} \mathrm{C}$ followed by a three-time washing step with PBS. After incubation with the Cy3 conjugated donkey antimouse IgG secondary antibody (1:200 dilution; Dianova, Hamburg, Germany) for $45 \mathrm{~min}$, the cells were washed again three times with PBS. To label F-actin, a 1:40 dilution of Alexa Fluor 488 phalloidin (Thermo Fisher Scientific) was added followed by DNA counterstaining during the mounting step with Fluoromount G (Invitrogen Life Technologies, Thermo Fisher Scientific, Schwerte, Germany) containing DAPI at a suitable working concentration. Stained cell samples were analyzed with a Leica TCS SP8 laser scanning confocal microscope and processed using Corel DRAW x7 with slight alterations to brightness and contrast.

\section{Detection of Intracellular Virus Genome Copies}

Viral genome copies were determined after isolation of total cellular RNA by ReliaPrep ${ }^{\text {TM }}$ RNA Miniprep System (Promega) followed by one-step Taq Man RT-qPCR as described previously (15).

\section{Measurement of TNF- $\alpha$ and IFNs in Culture Supernatants}

TNF- $\alpha$ and IFNs were determined in culture supernatants of MФ $\left(5 \times 10^{5} / \mathrm{ml}\right)$ using a human TNF- $\alpha$ ELISA (PeproTech) or a LEGENDPLEX human type 1/2/3 Interferon panel (5-plex) kit (BioLegend), respectively according to the manufacturer's protocol.

\section{Western Blot Analysis}

Western blot analysis was carried out as described previously (12). After washing with PBS, MФ $\left(5 \times 10^{5}\right)$ on culture plates were suspended in $100 \mu \mathrm{l}$ RIPA buffer $(50 \mathrm{mM}$ Tris, $150 \mathrm{mM}$ $\mathrm{NaCl}, 1 \%$ Nonidet P 40, 0.5\% deoxycholate, 0.1\% SDS; pH 7.5) supplemented with Complete EDTA-free protease inhibitor cocktail (Roche Diagnostics, Mannheim, Germany) and with phosphatase inhibitors ( $1 \mathrm{mM} \mathrm{Na}_{3} \mathrm{VO}_{4}$ and $50 \mathrm{mM} \mathrm{NaF}$ ). After sonication on ice, samples were centrifuged for $5 \mathrm{~min}$ at 15,000 g and $4^{\circ} \mathrm{C}$. In resulting supernatants protein concentrations were determined using a DC Protein Assay (Bio-Rad, Hercules, CA, USA) according to the manufacturer's protocol. Cell lysates (25$30 \mu \mathrm{g}$ ) were boiled in $1 \times$ Laemmli sample buffer, run on a $12 \%$ SDS-polyacrylamide gel (Protean II, Bio-Rad GmbH) and transferred to polyvinylidene difluoride membranes (PVDF membrane, Amersham Biosciences, Munich, Germany).

After blocking with 5\% milk powder, PVDF membranes were probed with the following antibodies: anti-phospho-Stat-1 rabbit $\mathrm{Ab}$ (Tyr701, D4A7, 1: 1,000); anti-phospho-NF- $\mathrm{BB}$ rabbit Ab (p65, Ser536, 93H1, 1: 1,000); anti-phospho-TBK1 rabbit Ab (Ser172, D52C2 XP $\left.{ }^{\circledR}, 1: 1,000\right)$; anti-phospho-ERK1/2 mouse Ab (Thr202/ Tyr204, E10, 1: 2,000); anti-phospho-c-Jun amino-terminal kinase (JNK) rabbit Ab (Thr183/Tyr185, 81E11, 1: 1,000) (all from Cell Signaling, Danvers, MA, USA), anti-rubella (E1) mouse Ab (1: 500, Merck, Darmstadt, Germany) or anti- $\beta$-actin mouse Ab (clone AC 74, 1: 2,000, Sigma-Aldrich, St. Louis, USA). Primary Antibody were detected with the following POD-conjugated secondary antibodies: goat anti-rabbit IgG Ab (1: 20,000, Dianova) or goat anti-mouse IgG Ab (1: 8,000, Sigma-Aldrich, St. Louis, USA). Chemiluminescent detection on membranes by using ECL-A/ ECL-B substrate (both from Sigma Aldrich) or SuperSignal West Femto Maximum Sensitivity Substrate (Thermo Fisher Scientific) were analyzed on a CCD-camera Stella (raytest Isotopenmessgeräte $\mathrm{GmbH}$, Straubenhardt, Germany). For Densitometric analysis, the AIDA Image Analyzer Software (Elysia-raytest GmbH, Straubenhardt, Germany) was used and sample values were expressed as density relative to $\beta$-actin. For stripping the membrane, blots were washed $5 \mathrm{~min}$ with distilled water followed by a 3 times incubation with $0.1 \mathrm{M}$ glycine- $\mathrm{HCl}$ ( $\mathrm{pH} 2.0)$ for 5 min. After an additional washing step, membranes were again blocked with 5\% milk powder before re-probing with the next primary antibody.

\section{RNA Isolation and Reverse Transcription}

Macrophages $\left(3 \times 10^{5}\right)$ were washed with PBS and total RNA was isolated using the RNeasy Mini Kit (Qiagen, Hilden, Germany), according to the manufacturer's protocol. DNase I treatment and reverse transcription of equal amounts of RNA (at least $250 \mathrm{ng}$ ) to cDNA were performed as previously described (12). 


\section{Real-Time PCR (qPCR)}

For real-time PCR $1.5 \mu \mathrm{l}$ of cDNA template were added to a reaction mixture containing $7.5 \mu \mathrm{l}$ of the SYBR Green PCR mastermix (Bio-Rad, Hercules, CA, USA), $250 \mathrm{nM}$ forward and reverse primers (see below) in a final volume of $15 \mu \mathrm{l}$. The following primers were used: GNB2L1 (fwd 5 ' GAGTGTGGCCTTCTCCTCTG-3 ; rev 5'-GCTTGCAGTTA GCCAGGTTC-3`) (16), IFN- $\beta$ (fwd 5 '-AACTTTGACATCCC TGAGGAGATTAAGCAG-3'; rev 5 '-GACTATGGTCCAGGC ACAGTGACTGTACTC-3`) (17), IFN- $\lambda 1$ (fwd $5{ }^{`}$-GCAGGTTC AAATCTCTGTCACC-3`; rev 5`-AAGACAGGAGAGCTGC AACTC-3`) (18), IFNAR1 (fwd 5`'TCAGGTGTAGAAGAAA GGATTGAAA-3`; rev 5`-AGACACCAATTTTCCATGACGT A-3') (19), IFNLR1 (fwd 5`'TGGGTGGAGTCCGAATACCT3'; rev 5 '-GAGTGATCTGGACTGGCTGG-3`).

IFNLR1 primers were designed using the BLAST and the Primer3 program. The PCR reactions were performed using the CFX connect real-time PCR detection system (Bio-Rad, Hercules, CA, USA) according to the following protocol: initial denaturation at $95^{\circ} \mathrm{C}$ for $10 \mathrm{~min}$, followed by 40 cycles at $95^{\circ} \mathrm{C}$ for $15 \mathrm{~s}$ (denaturation), at $60^{\circ} \mathrm{C}$ for $30 \mathrm{~s}$ (primer annealing) and at $72^{\circ} \mathrm{C}$ for $30 \mathrm{~s}$ (extension/synthesis). Product quantification was carried out at $72^{\circ} \mathrm{C}$. Negative controls using water as template were run under the same conditions. Gene expression was calculated using the $\Delta \Delta \mathrm{Ct}$ method as previously described with GNB2L1 (Guanine nucleotide-binding protein subunit beta-2like 1) as the reference gene (20).

\section{Metabolic Assessment Through Extracellular Flux Analysis: Analysis of the Oxygen Consumption Rate (OCR) and the Extracellular Acidification Rate (ECAR)}

The OCR and ECAR were measured using an XFp analyzer (Agilent Seahorse Technologies, Santa Clara, CA, USA). XFp Seahorse plates were seeded with $\mathrm{M} \Phi(200 \mu \mathrm{l}$ per well $)$ at a density of $2 \times 10^{5} / \mathrm{ml}$. After $2 \mathrm{~h}$ cells were analyzed or subjected to virus infection. Thereafter culture medium was replaced by XF base medium (Agilent Seahorse Technologies) supplemented with $2 \mathrm{mM}$ glutamine and $11 \mathrm{mM}$ glucose. The cells were then incubated at $37^{\circ} \mathrm{C}$ in a $\mathrm{CO}_{2}$-free incubator for 45 to $60 \mathrm{~min}$. Hereafter basal OCR and ECAR were determined in the XFp analyzer, before LPS $(100 \mathrm{ng} / \mathrm{ml})$ was injected (measurement point 6). Further measurements were taken for another $1 \mathrm{~h}$. Agilent Seahorse software Wave 2.3 was used for data analysis.

\section{Statistical Analysis}

Statistical analysis was done using GraphPad PRISM or SigmaPlot ${ }^{\circledR}$ software. Statistical significance was calculated with Student's $t$-test or ANOVA test as indicated in the respective figure legend. Statistical significance is classified as follows: ${ }^{\star} \mathrm{p} \leq 0.05,{ }^{* *} \mathrm{p} \leq 0.01,{ }^{* * *} \mathrm{p} \leq 0.001$. ANOVA test of percentage or fold change data was performed after $\log$ transformation.

\section{RESULTS}

\section{RV Infection and Cytokine Response}

Before infecting cells we verified the well documented phenotypical characteristics of GM- and M-MФ (21) by showing that M-M $\Phi$ specifically expressed CD163 (M-MФ $613.5 \pm 663.6$; GM-MФ $23.5 \pm 15.2$ ) and CD14 (M-MФ 5094.0 \pm 773.7; GM-MФ 1700.3 \pm 933.1), while expression levels of CD80 (GM-MФ $31.7 \pm 8.4$; M-MФ $7.0 \pm 7.2$ ) and CD40 (GM$\mathrm{M} \Phi 167.7 \pm 29.3$; M-MФ $65.7 \pm 17.0)$ were constitutively higher on GM- than on M-MФ. Based on recent findings, showing that after RV-infection neither the amount of extracellular virus particles nor the number of RV-positive cells varied between GM- and M-MФ (11), we here examined the cellular morphology of both subsets after infection with RV by staining of F-actin. We found cluster formation (Figure 1A) which was slightly more prevalent in M-M $\Phi$ than in GM-M $\Phi$.

Similar to RV, UV-inactivated RV (UV-RV) was detected in both cell types. However, the genome copies, which hardly varied between GM- and M-M $\Phi$ were 2 to 3 log steps lower than after $\mathrm{RV}$ infection indicating that UV-RV does not replicate within the cell and that the copies reflect the original incoming virus genome (Figure 1B).

The fact that UV-RV is taken up by human $M \Phi$ without initiation of RV replication and that UV-RV contains the virion components as well as factors released from Vero cells during virus stock preparation, make it a useful control when studying $\mathrm{RV}$ infection.

According to the time course of virion production performed over $24 \mathrm{~h}$ the number of infectious virus particles generated by GM- and M-MФ was almost identical between 4 and 24 h post infection (hpi) (Figure 1C). At $6 \mathrm{hpi}$ the number slightly decreased (indicating the eclipse phase) and at 24 hpi after a delay phase between 8 and 12 hpi virion production and release to the medium were increased.

The similarity of RV replication rates between GM-MФ and MM $\Phi$ was also reflected by expression levels of viral E1 protein as detected by western blot analysis at $24 \mathrm{hpi}$ (Figure 1D). Thus, possible differences between GM- and M-M $\Phi$ in LPS-induced responses are unlikely to be due to differences in the course of infection.

Next, we determined the impact of RV infection on the inflammatory response of GM- and M-M $\Phi$ by analyzing the production of the cytokines TNF- $\alpha$, IFN- $\alpha 2$ and IFN- $\beta$ (type I), IFN- $\gamma$ (type II), IFN- $\lambda 1$ and $\lambda 2 / 3$ (type III). IFN- $\gamma$ and IFN- $\lambda 2 / 3$ were not detectable under any assay conditions.

As seen in Figure 1E, RV induces TNF- $\alpha$ production in both subtypes, the amounts secreted by $\mathrm{M}-\mathrm{M} \Phi$ slightly exceeding those of GM-MФ.

GM- and M-M $\phi$ also responded to the RV-infection with an increase in IFN- $\alpha 2$, IFN- $\beta$ and IFN- $\lambda 1$ concentrations (Figure 1F), whereas no IFN- $\gamma$ was detectable (data not shown).

The observation that the increase of virion production (Figure 1C) also started $12 \mathrm{hpi}$ and that a medium change carried out 12 hpi had no inhibitory effect on RV-induced IFN production (except IFN- $\beta$ ) (Figure 1G) points to a close relation between virion generation and IFN production. M-MФ 
A

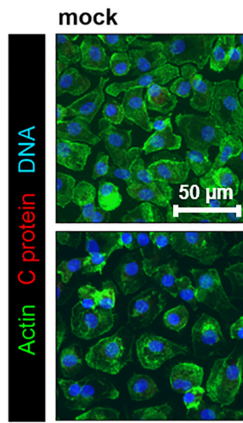

D

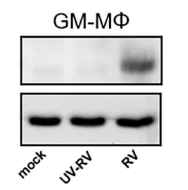

E

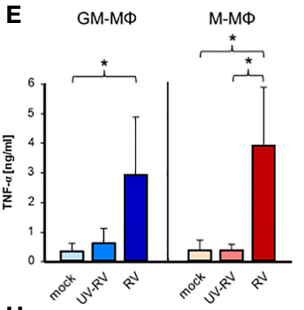

$$
\text { H }
$$

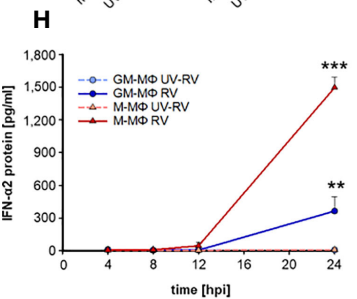

RV

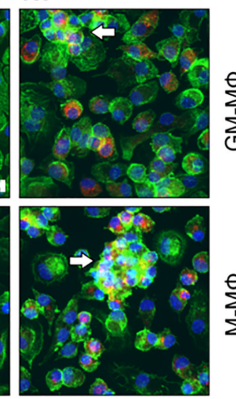

$M-M \Phi$

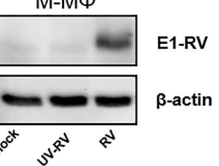

$\sum_{0}^{\theta}$

B

C

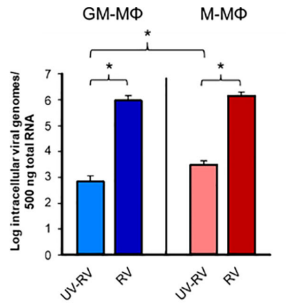

$\sum_{i}^{\ominus}$

$\mathbf{F}$

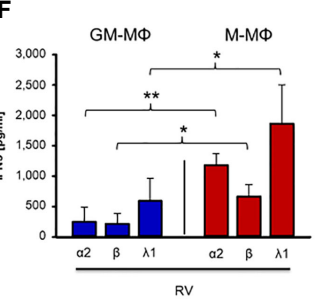

G

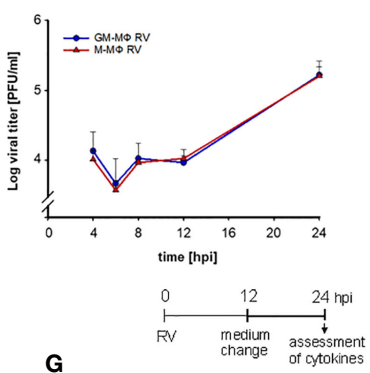

I

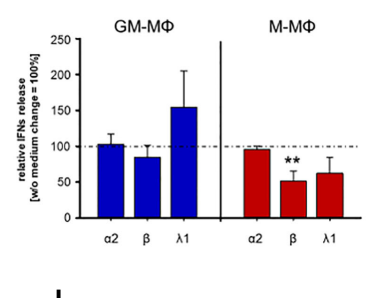

J

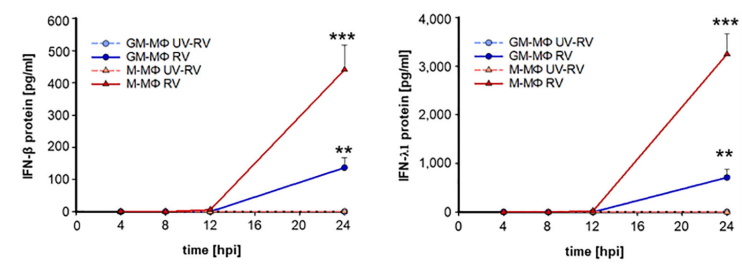

K

$\mathbf{L}$

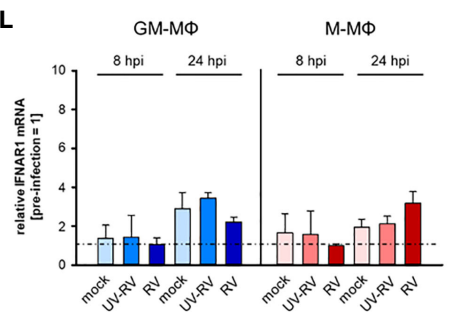

FIGURE 1 | Kinetics of RV replication and RV-induced cytokine response in human MФs. (A) Immunofluorescence staining of capsid protein (C protein, red), actin

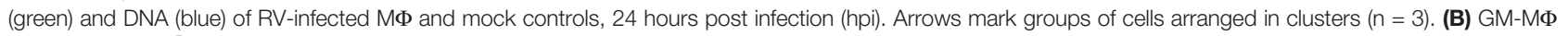
and $\mathrm{M}-\mathrm{M} \Phi\left(5 \times 10^{5} / \mathrm{ml}\right)$ were infected with RV or ultraviolet light-inactivated RV (RV-UV) and the number of intracellular viral genome copies was determined by quantitative one-step TaqMan PCR at 24 hpi. Data represent means \pm SD $(n=3)$. Statistical analysis was performed using the ANOVA test. (C) Assessment of

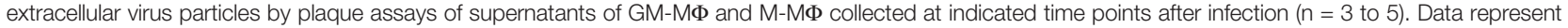
means \pm SD. (D) Cells $\left(5 \times 10^{5} / \mathrm{ml}, 24 \mathrm{hpi}\right)$ were lysed using RIPA buffer and proteins separated by SDS-PAGE were subjected to western blot analysis using antibodies for the rubella E1 structure protein and $\beta$-actin. One representative blot out of three is shown. At 24 hpi (E) secreted TNF- $\alpha$ was determined by ELISA $(n=6$, means $\pm S D$ ) and $(\mathbf{F})$ IFN protein levels by LEGENDPLEX human interferon panel kit $(n=3$, means \pm SD). Statistical analysis for $(\mathbf{E}, \mathbf{F})$ were performed using the ANOVA test. (G) At 12 hpi the medium was changed and the cells were incubated for another $12 \mathrm{~h}$. At 24 hpi the amount of IFNs produced after a medium change (12 hpi) was calculated as fold induction without medium change $(=100 \%)$. Data represent means \pm SD $(n=3)$. Statistical analysis was performed using the ANOVA test. At indicated time points the protein expression levels of IFN- $\alpha 2(\mathbf{H})$, IFN- $\beta$ (I) and IFN- $\lambda 1$ (J) were quantified by LEGENDPLEX human interferon panel kit. Data represent means $\pm S D(n=3)$. Student's $t$-test and significances were calculated to M $\Phi$ treated with RV-UV. IFNLR1 (K) and IFNAR1 (L) mRNA expression were determined by qPCR before RV infection as well as 8 and 24 hpi. Data are presented as relative mRNA expression of pre-infected M $M(=1)(n=3$, means $\pm S D)$ ${ }^{*} \mathrm{p} \leq 0.05,{ }^{* \star} \mathrm{p} \leq 0.01,{ }^{* \star *} \mathrm{p} \leq 0.001$ 
produced far more IFNs than GM-M $\Phi$, the concentrations of IFN- $\lambda 1$ being highest in both subtypes. UV-RV and mock controls did not produce any IFNs.

These differences in IFN- $\alpha 2,-\beta$ and $-\lambda 1$ production can hardly be explained by the kinetics of their release. Secretion of all three IFNs started at $12 \mathrm{hpi}$ and high concentrations were reached at 24 hpi (Figures $\mathbf{1} \mathbf{H}-\mathbf{J}$ ).

As the expression levels of IFN-receptors play an important role for the production of IFNs in a positive feedback loop we determined the mRNA receptor levels of type III interferonlambda receptor 1 (IFNLR1) and type I interferon- $\alpha / \beta$ receptor 1 (IFNAR1) before infection with RV as well as at 8 and 24 hpi. Before starting the experiments, we addressed the expression level of both types of receptors and showed that they hardly

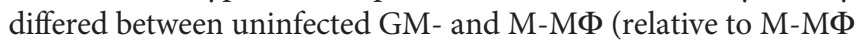
expression $=1$, GM-MФ IFNAR $=0.95 \pm 0.14$, IFNLR1 $=1.24 \pm$ $0.16)$. At 24 hpi IFNLR1 transcripts increased in GM- and M$\mathrm{M} \Phi$ about 5- and 3-fold respectively as compared to $0 \mathrm{~h}$ controls (before treatment) (Figure $\mathbf{1 K}$ ) and at 8 hpi only a minor increase was observed in M-M $\Phi$.

We also found IFNAR1 transcript to be moderately elevated in both subtypes at $24 \mathrm{hpi}$; the small rise at $8 \mathrm{hpi}$ was restricted to mock- and UV-RV-infected controls (Figure 1L). However, as the RV-induced rise of both IFN receptor transcripts in GM- and $\mathrm{M}-\mathrm{M} \Phi$ also occurred in mock and UV-RV, a correlation between increased mRNA levels of the receptors and an elevated RVinduced IFN-response cannot be drawn.

These data show that RV infects GM- and M-MФ to a similar extent and that both subtypes are competent to respond to RV mounting a cytokine response consisting of a release of a relative minor elevated TNF- $\alpha$ production and an increase in type I IFNconcentrations, the latter being more pronounced in M-MФ than in GM-MФ.

\section{RV Supports IFN-Production After a Secondary Exposure to LPS}

Having shown that RV induces TNF- $\alpha$ and IFN-production in both M $\Phi$ subtypes we next tested whether stimulation with LPS after RV infection affects the outcome of the cytokine response.

Therefore, cells were infected with RV and the respective controls (mock, UV-RV) for $24 \mathrm{~h}$ before fresh medium with or without LPS was added for another 6 h. As seen in Figure 2A, GM- and M-M $\Phi$ infected with RV only, produced small amounts of TNF- $\alpha$ (see Table 1, Figure 2A). The TNF- $\alpha$ levels increased after exposure to LPS, the rise being largely independent of the viral infection, albeit a small but insignificant increase was observed in M-M $\Phi$ after RV infection (Figure 2A).

Both subtypes secreted small amounts of IFNs (except for IFN- $\beta$ in GM-MФ) after RV infection in the absence of LPS (Figure 2B, Table 1). However, addition of LPS to the infected cells resulted in an increase of IFN- $\beta$ and IFN- $\lambda 1$, but not of IFN$\alpha 2$ levels. Neither UV-RV infected (data not shown) nor mock controls (Table 1) produced any IFNs in response to LPS.

As IFN- $\beta$, known to act in an autocrine fashion (22), was produced by GM- and $\mathrm{M}-\mathrm{M} \Phi$ in response to $\mathrm{RV}$-infection (Figure 1F), we tested whether it can mimic the effects of RV on LPS-induced cytokine production when added exogenously. We found that IFN- $\beta(20 \mathrm{ng} / \mathrm{ml})$ did not induce TNF- $\alpha$ production whereas after challenge with LPS the TNF- $\alpha$ levels increased, in M-M $\Phi$ similar to controls and in GM-M $\Phi$ even less (Figure 2A). Treatment with IFN- $\beta$ also failed to induce IFN production (Figure 2B). Only after exposure to LPS IFN- $\beta$ and IFN- $\lambda 1$ levels increased, IFN- $\alpha 2$ levels were unaffected. The small amounts of IFN- $\beta$ present in the absence of LPS likely stem from the added IFN- $\beta$ (Figure 2B).

When diluting IFN- $\beta$ concentrations starting with $20 \mathrm{ng} / \mathrm{ml}$ the LPS-induced enhancement of IFN- $\beta$ and IFN- $\lambda 1$ production decreased in a concentration dependent manner (Figures 2C, D). As little as 0.2 to $0.02 \mathrm{ng} / \mathrm{ml}$ were sufficient to amplify the IFN- $\beta$ and $-\lambda 1$ response. M-M $\Phi$ produced slightly more IFN- $\beta$ and $-\lambda 1$ than GM-M $\phi$ and the IFN- $\lambda 1$ release always exceeded that of IFN- $\beta$.

As seen in Figures 2E, F exposure of GM- and M-MФ to small concentrations $(0.2$ to $0.02 \mathrm{ng} / \mathrm{ml})$ of IFN- $\beta$ results in low phosphorylation levels of Stat1, sufficient for enhanced responsiveness to the secondary stimulus LPS (Figures 2C, D).

Taken together our data show that RV-infection hardly effects the LPS-induced TNF- $\alpha$ production and that the virus primes both subtypes to produce appropriate amounts of IFN- $\beta$ and $-\lambda 1$ in response to LPS. The same holds true at least for IFN- $\beta$ and $-\lambda 1$ production when RV is replaced by IFN- $\beta$.

Next, we tested whether the priming effect of RV on IFN- $\beta$ and $-\lambda 1$ production also occurred at the mRNA level. The mRNA expression of IFN- $\beta$ (Figure 3A) and $-\lambda 1$ (Figure 3B) started to increase at $8 \mathrm{hpi}$ and $12 \mathrm{hpi}$ in $\mathrm{M}$ - and GM-M $\Phi$ respectively and continued to rise up to $24 \mathrm{hpi}$. At all time points the values reached by $M-M \Phi$ exceeded those of GM-M $\Phi$ (Figures 3A, B). Negligible amounts of IFN-mRNA were produced after UV-RV infection. Extending the incubation time for another $6 \mathrm{~h}$ after medium change, in the presence of LPS resulted in a further increase of IFN- $\beta$ (Figure $3 \mathrm{C}$ ) and $-\lambda 1$ (Figure 3D) mRNA in both $M \Phi$ subtypes.

The mRNA level of IFN- $\beta$ in LPS challenged GM- and M$M \Phi$ peaked after $2 \mathrm{~h}$ and reached basal values after $6 \mathrm{~h}$. IFN- $\lambda 1$ mRNA expression, however, peaked after $4 \mathrm{~h}$ in both subtypes and declined thereafter. In the absence of LPS the production of IFN- $\beta$ and $-\lambda 1$ mRNA remained at a rather constant level (Figures 3C, D).

Thus, IFN- $\beta$ and $-\lambda 1$ protein kinetics up to $24 \mathrm{hpi}$ (Figures 1I, J) clearly reflect the corresponding mRNA expression levels (Figures 3A, B) and the IFN- $\beta$ and $-\lambda 1$ mRNA levels as well as the protein concentrations reached by M-MФ $6 \mathrm{~h}$ after exposure to LPS both exceeded those of GM-MФ (Table 1).

Taken together these data demonstrate that RV as well as IFN- $\beta$ regulate the IFN-production in response to a secondary challenge with LPS. Under assay conditions that result in a very low LPS-induced IFN-production the virus primes both macrophage subsets to react to LPS treatment with a rise in IFN concentrations. The same holds true when substituting RV by IFN- $\beta$. Notably low concentrations of IFN- $\beta(\mathrm{pg} / \mathrm{ml})$ are sufficient for enhanced LPS-induced responsiveness to this cytokine. 


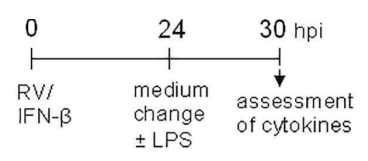

A

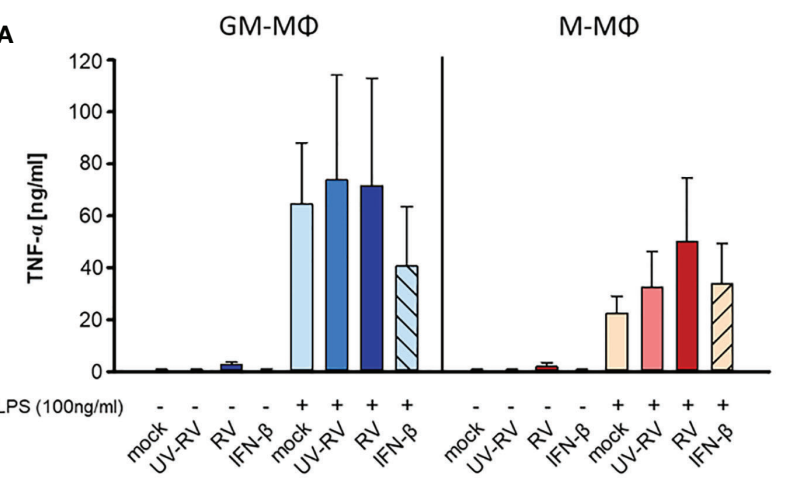

B

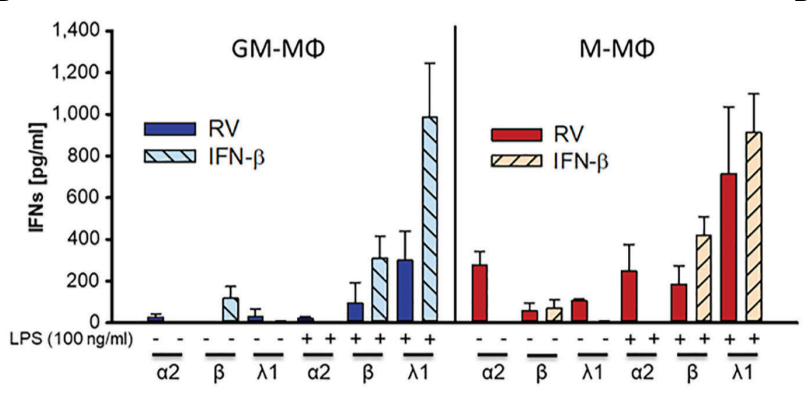

E

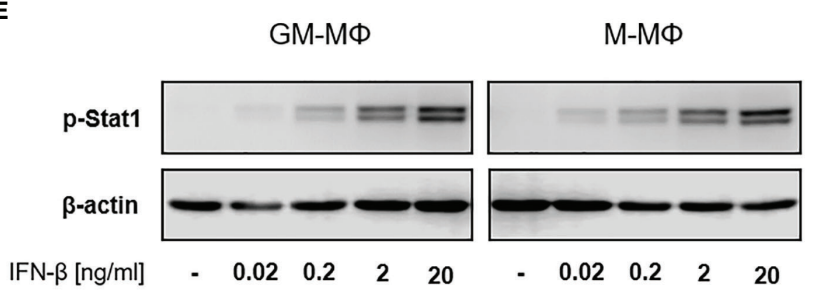

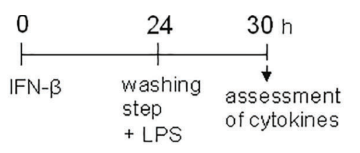

C

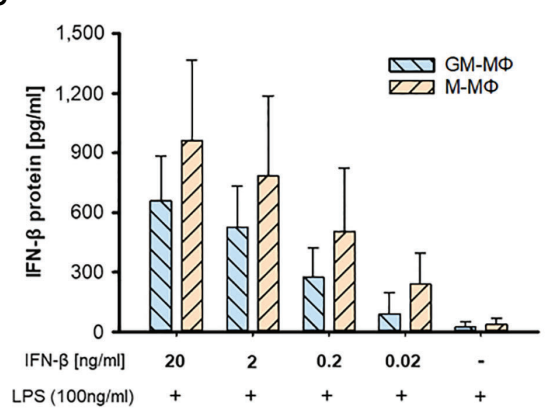

D

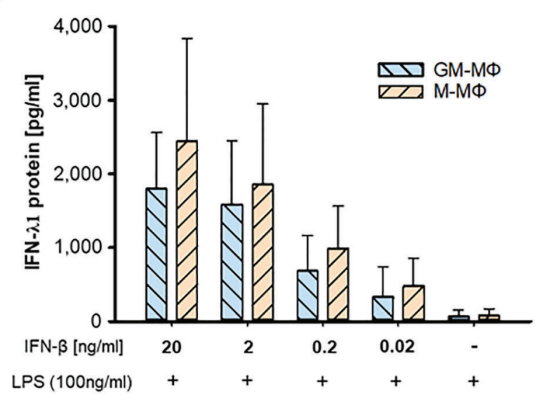

F

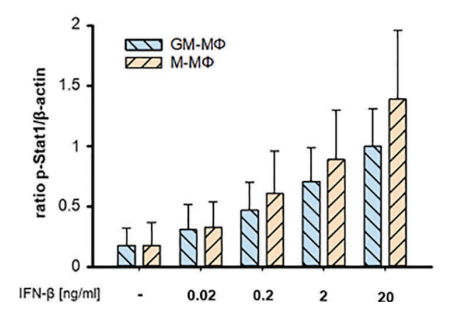

FIGURE 2 | LPS-induced cytokine response after infection with RV and IFN- $\beta$. At $24 \mathrm{~h}$ after incubation of mock, UV-RV, RV and IFN- $\beta$ (20 ng/ml) treated

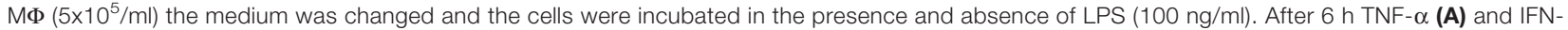
concentrations (B) in the culture supernatants were determined by ELISA and LEGENDPLEX human interferon panel kit, respectively. Data represent means

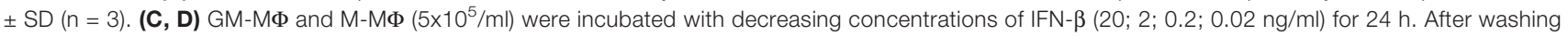
with PBS cells were stimulated with LPS (100 ng/ml) for $6 \mathrm{~h}$. IFN-concentrations were determined by LEGENDPLEX human interferon panel kit. Data

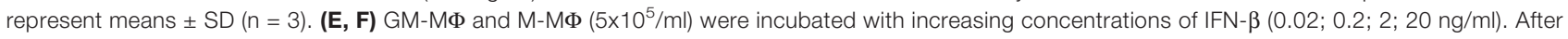
$24 \mathrm{~h}$ cells were lysed using RIPA buffer and proteins separated by SDS-PAGE were subjected to western blot analysis using antibodies for $\mathrm{p}$-Stat1 and $\beta$ actin. One representative blot out of three is shown (E). (F) Western blot bands were quantified and $p$-Stat1 normalized to loading control $\beta$-actin. Data represent means $\pm S D(n=3)$.

\section{RV Impairs LPS-Induced ERK1/2 Activation}

Having shown that exposure to LPS following infection with rubella alters the biological response of GM-MФ and M-MФ we tested whether distinct components of the virus and LPSdependent signalling pathways are affected by the treatment. The role played by components in these pathways is outlined in a short and simplified way in Figure 4.
As shown in Figures 5A, B we found the transcription factor $\mathrm{NF} \kappa \mathrm{B}$ to be phosphorylated in response to RV infection. NFKB plays an important role in the gene-regulatory network in immune responses including the induction of the genes that encode IFN- $\beta$ and pro-inflammatory cytokines $(32,33)$. It associates with the transcription factors AP1 and IRF3 resulting in the direct binding and activation of the IFN- $\beta$ promoter (34). 
TABLE 1 | LPS-induced cytokine response of RV-infected MФ.

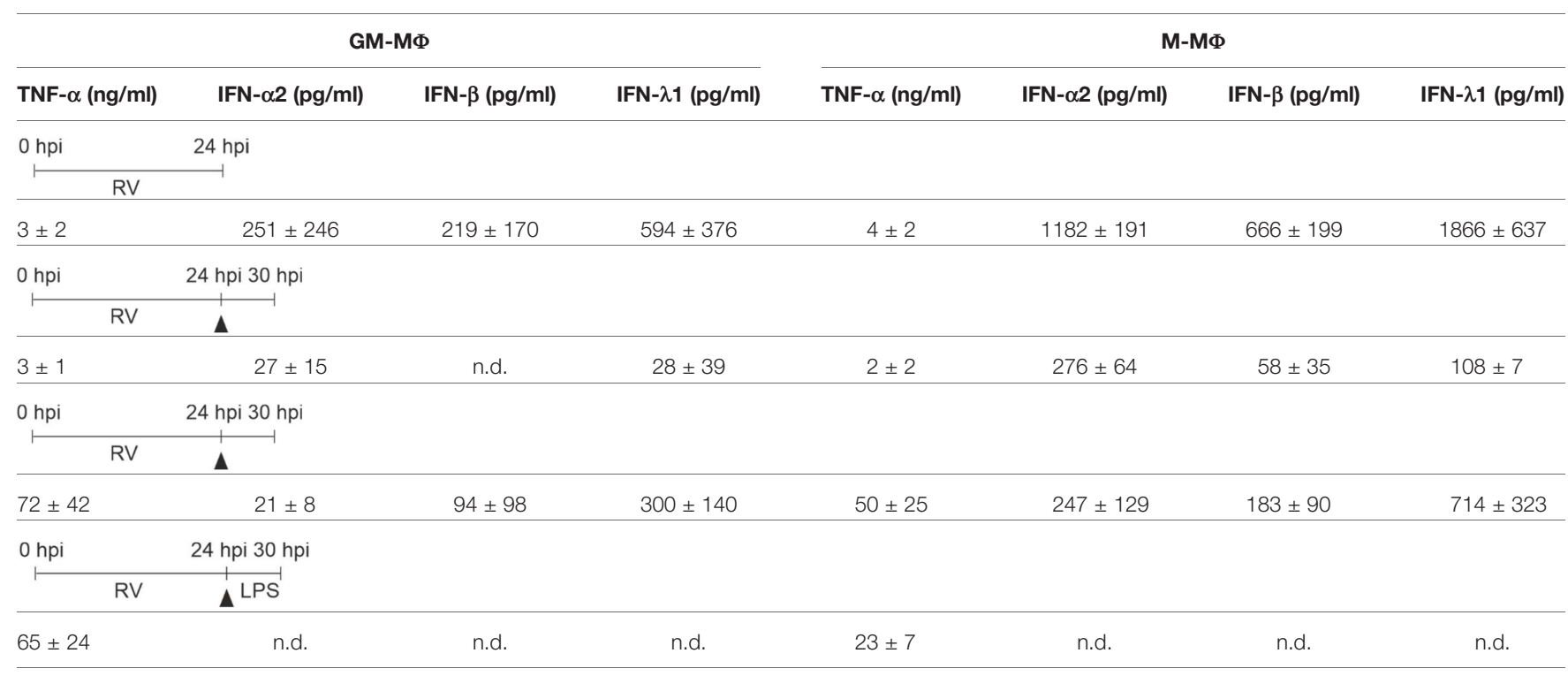

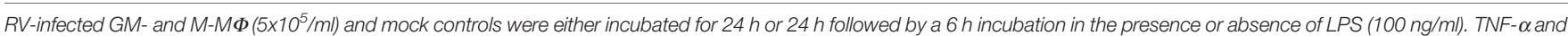
IFNs concentrations were determined in culture supernatants by ELISA and LEGENDPLEX human interferon panel kit, respectively ( $n=3 ;$ means \pm SD). The experimental set-up is visualized by a graphical scheme. Arrow heads indicate medium change with or without addition of LPS. The last time point in the graphical scheme refers to the time point of analysis. n.d., Not detectable.

After RV-infection we detected only minor amounts of phosphorylated TBK1 (Figure 5A), a central kinase in the pathway leading to type I IFN-production. However, p-Stat1 expression was greatly enhanced in both $M \Phi$ subtypes, which was consistent with an increased production of IFNs following infection with RV.

Next, we tested the effect of LPS on the phosphorylation profile of NFKB, ERK1/2, JNK, TBK1 and Stat1 when applied $24 \mathrm{~h}$ after virus infection.

As shown in Figures 5A, C treatment of controls (mock, UVRV) with LPS had no effect on Stat1 phosphorylation and led to an increased phosphorylation of NFKB, ERK1/2, JNK and TBK1, indicating that both TLR4 dependent pathways have been engaged.

Prior infection with $\mathrm{RV}$ resulted in an increased

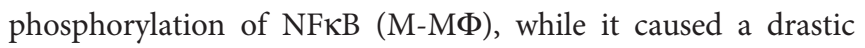
downregulation of p-ERK1/2 in both subtypes. This effect was also slightly visible in the absence of LPS challenge.

In conclusion, an established RV infection leads to a decrease of the LPS-induced ERK1/2 phosphorylation in both MФ subtypes.

\section{RV Dampens LPS-Induced Glycolysis}

Having shown that exposure of GM- and M-M $\Phi$ to RV prior to incubation with LPS results in an enhanced production of IFNs, we asked whether activation by the respective stimuli alone or applied successively is associated with metabolic changes.

To determine the metabolism of GM- and M-M $\Phi$ after RVinfection followed by exposure to LPS we measured extracellular acidification rate (ECAR) as an index of lactic acid production and oxygen consumption rate (OCR) as an index of oxidative phosphorylation.
OCR and ECAR were measured every 6 min at 16 measurement points. As seen in Figures 6A-D GM-M $\Phi$ exhibited elevated basal OCR and ECAR levels compared to $M-M \Phi$ indicating that the bioenergetics profile differs between the twoM $\Phi$ subsets. Challenge with LPS for $0.5 \mathrm{~h}$ and $1 \mathrm{~h}$ induced a profound increase in ECAR in GM-MФ and to a lesser extent in M-M $\Phi$, whereas OCR remained unaffected (Figures 6B, D).

These data as illustrated in the Energy Phenotype Profile of ECAR and OCR (Figure 6E) demonstrate that M-MФ are in a more quiescent state than GM-MФ. In response to LPS GM-M $\Phi$ undergo metabolic reprogramming towards glycolysis slightly more than M-MФ.

As a next step, the bioenergetics profile that is reflected by the ratio of OCR and ECAR was determined in M $\Phi$ having been infected with RV and UV-RV for $24 \mathrm{~h}$ (Figure 6F).

The OCR/ECAR ratio serves as a useful parameter to compare metabolic states between different cell types (35). The lower the ratio, the higher the glycolytic activity.

The ratio analysis of GM- and M-MФ 24 hpi (Figure 6F) confirmed their metabolic identity, which relies on glycolysis and oxidative phosphorylation, respectively.

Notably in $M-M \Phi$, this ratio is lower after infection with RV than in the mock-control (Figure 6F) suggesting that during RVinfection glycolytic activity is increased in M-MФ.

When determining the metabolic activity after LPS-challenge OCR values slightly increased in RV- and to a lesser extent in UV-RV - and mock-infected GM-MФ whereas M-M $\Phi$ did not respond to LPS (Figure 6G).

Compared to basal OCR levels the rise at $0.5 \mathrm{~h}$ after treatment with LPS was only significant in RV-infected GM-MФ and at 24 hpi (Figure 6H). 
A

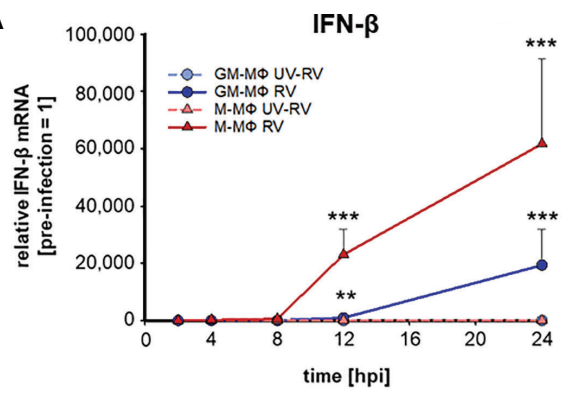

B

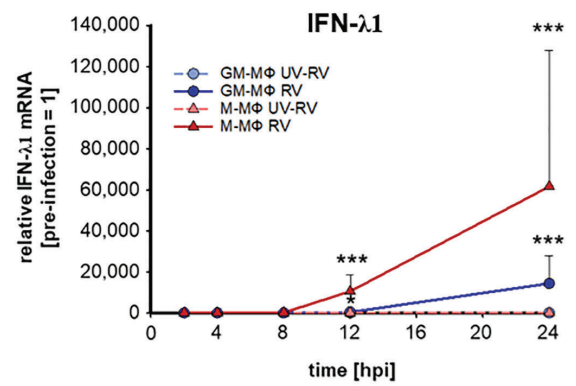

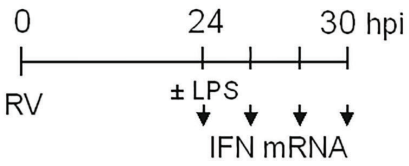

c

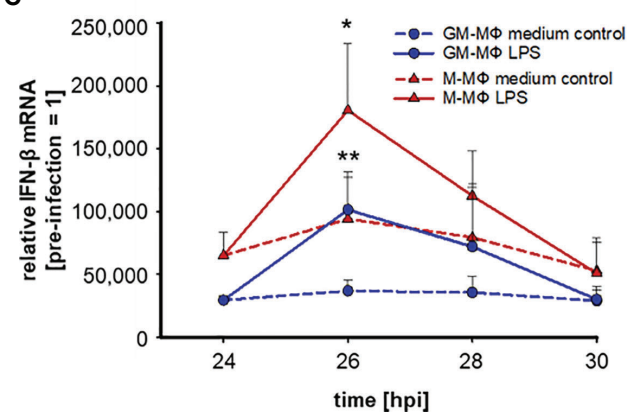

D

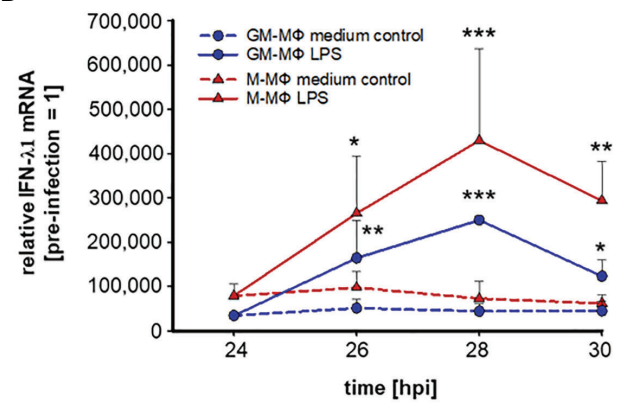

FIGURE 3 | LPS-induced IFN mRNA expression after infection with RV. RV and UV-RV-infected M $\Phi\left(5 \times 10^{5} / \mathrm{ml}\right)$ were incubated for $2,4,8,12$ and $24 \mathrm{~h}$. IFN- $\beta$ (A)

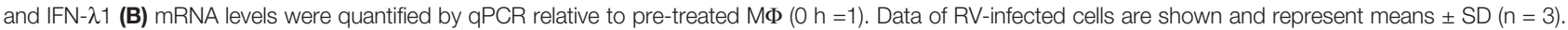
Statistical analysis was performed using the ANOVA test and significances were calculated to M $\Phi$ infected with RV-UV. At 24 hpi RV-infected cells were treated with medium (control, dashed line) or incubated with LPS (100 ng/ml) and subjected to RNA extraction after 2,4 and $6 \mathrm{~h}$ of incubation. IFN- $\beta$ (C) and IFN- $\lambda 1$ (D) mRNA levels were quantified by GPCR relative to pre-infected $M \Phi(O h=1)$. Data represent means $\pm S D(n=3)$. Statistical analysis was performed using the ANOVA test and significances were calculated to medium control. ${ }^{*} \mathrm{p} \leq 0.05,{ }^{* *} \mathrm{p} \leq 0.01,{ }^{* \star *} \mathrm{p} \leq 0.001$.

Independent of the preceding treatment both $\mathrm{M} \Phi$ subtypes responded to LPS with a substantial increase in ECAR levels (Figures 6I, J). In relation to basal ECAR the values reached $0.5 \mathrm{~h}$ after LPS treatment were significantly lower in RV-infected M $\Phi$ than in mock and UV-RV treated controls (Figure 6K).

Taken together these data indicate that stimulation with LPS resulted in a slight increase in glycolytic activity of both GM- and $M-M \Phi$. During RV-infection glycolytic activity was slightly increased in $\mathrm{M}-\mathrm{M} \Phi$, while in both cell types RV-infection significantly dampened the LPS-induced increase in glycolysis. This latter metabolic reprogramming indicates that RV signalling followed by LPS signalling results in a specific biological response, which is associated with a diminished glycolysis.

As an overall conclusion, the here presented data are summarized in Figure 7.

\section{DISCUSSION}

$\mathrm{M} \Phi$ as central components of the innate and adaptive immune response are well known for their antiviral functions (11). To what extent they contribute to RV pathogenesis and to the outcome of a viral response when being infected themselves is less well understood.

Here we show in line with previous reports (11) that RV infects GM- and M-M $\Phi$ and replicates within these cells. As described for other virus-related processes we show that productive virus replication which is missing after UV-induced $\mathrm{RV}$ inactivation is required to trigger TNF- $\alpha$ and IFNproduction in GM- and M-M $\Phi$ (1). Consistent with the cytokine profile of the two $M \Phi$ populations, $\mathrm{M}-\mathrm{M} \Phi$ produced far more IFNs than GM-M $\Phi$ in response to RV, confirming a more anti-viral response of $\mathrm{M}-\mathrm{M} \Phi$.

However, the TNF- $\alpha$ response was low compared to the amounts produced after exposure to LPS and differences between the two subtypes were hardly visible. Thus, the induction of this cytokine during RV infection does not represent a major component of the defense mechanism of RV-infected $M \Phi$.

Of the three IFNs tested, production of IFN- $\lambda 1$ (type III IFN) was found to be highest. A similar IFN-response profile was detected after infection of human alveolar basal epithelial A549 


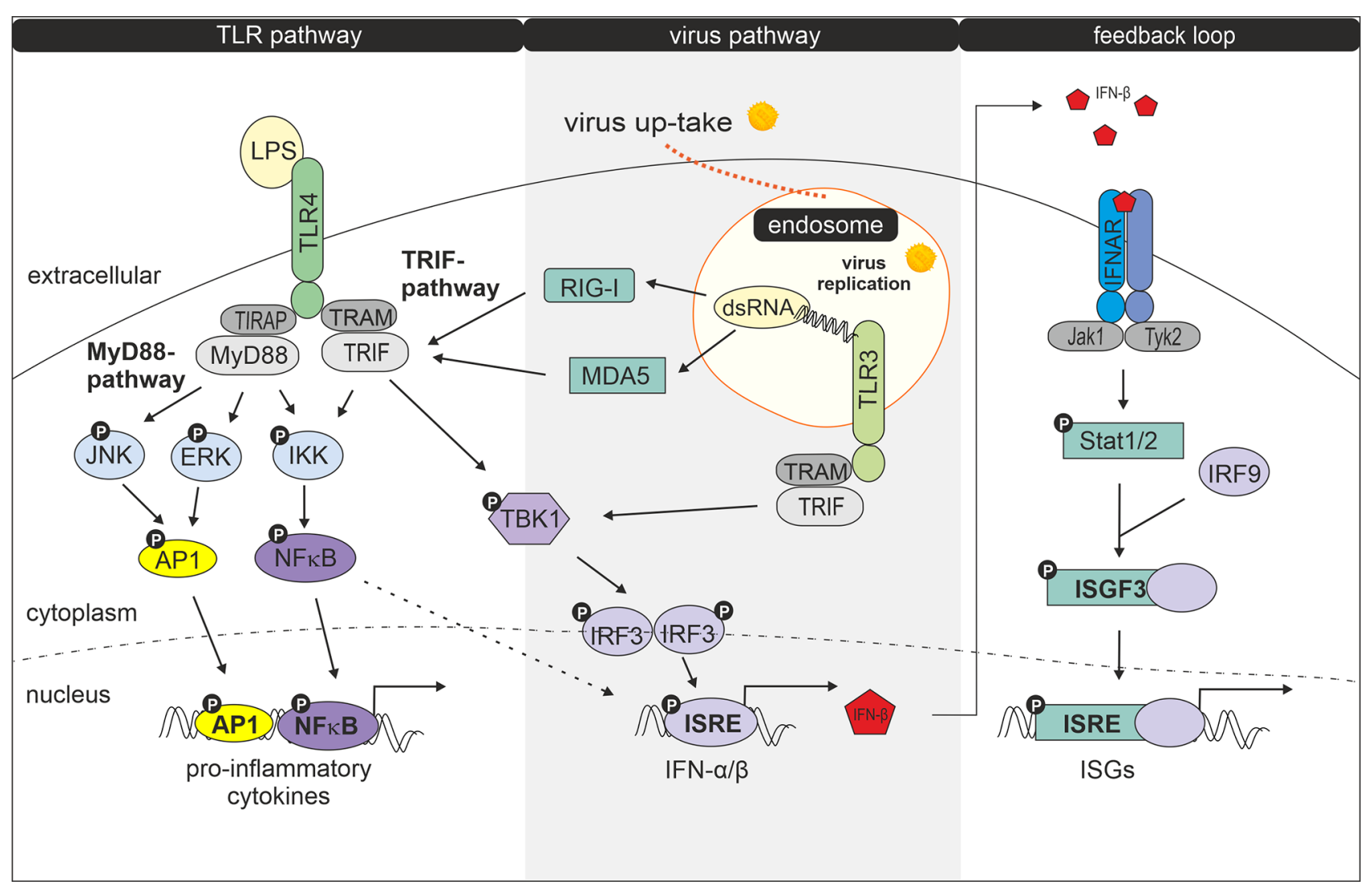

FIGURE 4 | Interaction of LPS- and virus-induced signalling pathways. Modified according to Randall et al. (23). Following uptake and replication of RV double stranded RNA (dsRNA) is generated. Recognition of dsRNA by cytosolic receptors MDA5 (melanoma differentiation-associated protein 5) and RIG-1 (retinoic acidinducible gene I) results in activation of TRIF, followed by activation of TANK-binding kinase 1 (TBK1), an enzyme that catalyses the phosphorylation of IRF-3 (interferon regulatory factor 3). Phosphorylated IRF-3 then forms dimers, which translocate to the nucleus and activate transcription of type I interferon genes (24, 25). Type I IFN production can be amplified by a positive feedback loop (26). Secreted IFNs bind and activate the type I IFN receptor IFNAR (interferon-alpha/beta IFN-receptor) leading to Stat1 (signal transducer and activator of transcription) and Stat2 phosphorylation via JAK protein kinase JAK1 and Tyk2. After dimerization Stat1 and Stat2 together with IRF9 forms the transcription factor complex ISGF3 (interferon-stimulated gene factor 3) which by binding to ISRE (IFN-stimulated response elements) induces expression of IFN-inducible genes (ISGs) $(27,28)$. Double stranded RV RNA can also enter endocytotic compartments where it is potentially recognized by TLR3. Upon ligand recognition TLR3 can recruit TRIF (TIR-domain-containing adapter-inducing interferon- $\beta$ ) and TRAM (TRIF- related adaptor molecule) (29) which signal for IRF3 activation and IFN- $\beta$ production. IRF3 becomes phosphorylated by TBK1 or IKK1 (IKB kinase 1) (24, 30, 31). After binding of LPS to the TLR4 complex, signalling occurs via two pathways: the MyD88 (myeloid differentiation factor 88) -TIRAP (TIR domain containing adaptor protein) and the TRAM-TRIF pathway (24). The MyD88-TIRAP pathway which is mainly but not entirely responsible for induction of pro-inflammatory cytokines involves activation of NFKB and AP1 and MAPKs such as extracellular signal-regulated kinase (ERK) and c-Jun N-terminal kinase (JNK) (29) while TRAM and TRIF after internalization of the LPS-TLR4 complex signal to TBK1 for IRF3 activation and primary IFN production (29).

cells with RV (11). Type III IFNs exhibit several common features with type I IFNs (IFN- $\alpha / \beta)$ (36). They appear to be induced by the same stimuli and similar to IFN- $\alpha / \beta$ they use the JAK/Stat signalling pathway. In contrast to IFN- $\alpha / \beta$ which binds to IFNAR, a receptor composed of the IFNAR1 and IFNAR2 chains $(37,38)$, IFN- $\lambda 1$ uses a receptor (IFNLR1) consisting of the IFNLR1 and IL-10R2 chain $(39,40)$. As the RV-induced production of IFNs can be amplified by a positive feedback loop through binding to the respective receptors as it was described for other virus infections $(27,28)$ we reasoned that expression levels of the receptor may contribute to the differences in the cytokine response by GM- and M-M $\Phi$. We found that IFNLR1 and IFNAR1 transcripts to be expressed at a similar level in both subtypes. However, the expression levels not only increased in $\mathrm{RV}$-infected cells during cultivation, but also in controls, indicating that the abundance of the IFNAR1 and IFNLR1 transcripts was not related to the IFN-response.

Next, we extended our studies by exposing RV-infected M $\Phi$ to a second stimulus to mimic co-infections and to characterize their inflammatory and metabolic status in association with a viral infection. We chose $\mathrm{RV}$ as a primary pathogen as RV replicates in both types of human $M \Phi$ and the bacterial component lipopolysaccharide (LPS) as a secondary stimulus and determined the response to the combined treatment. LPS, the major constituent of the outer membrane of all gramnegative bacteria, is a potent activator of $M \Phi$ responses 

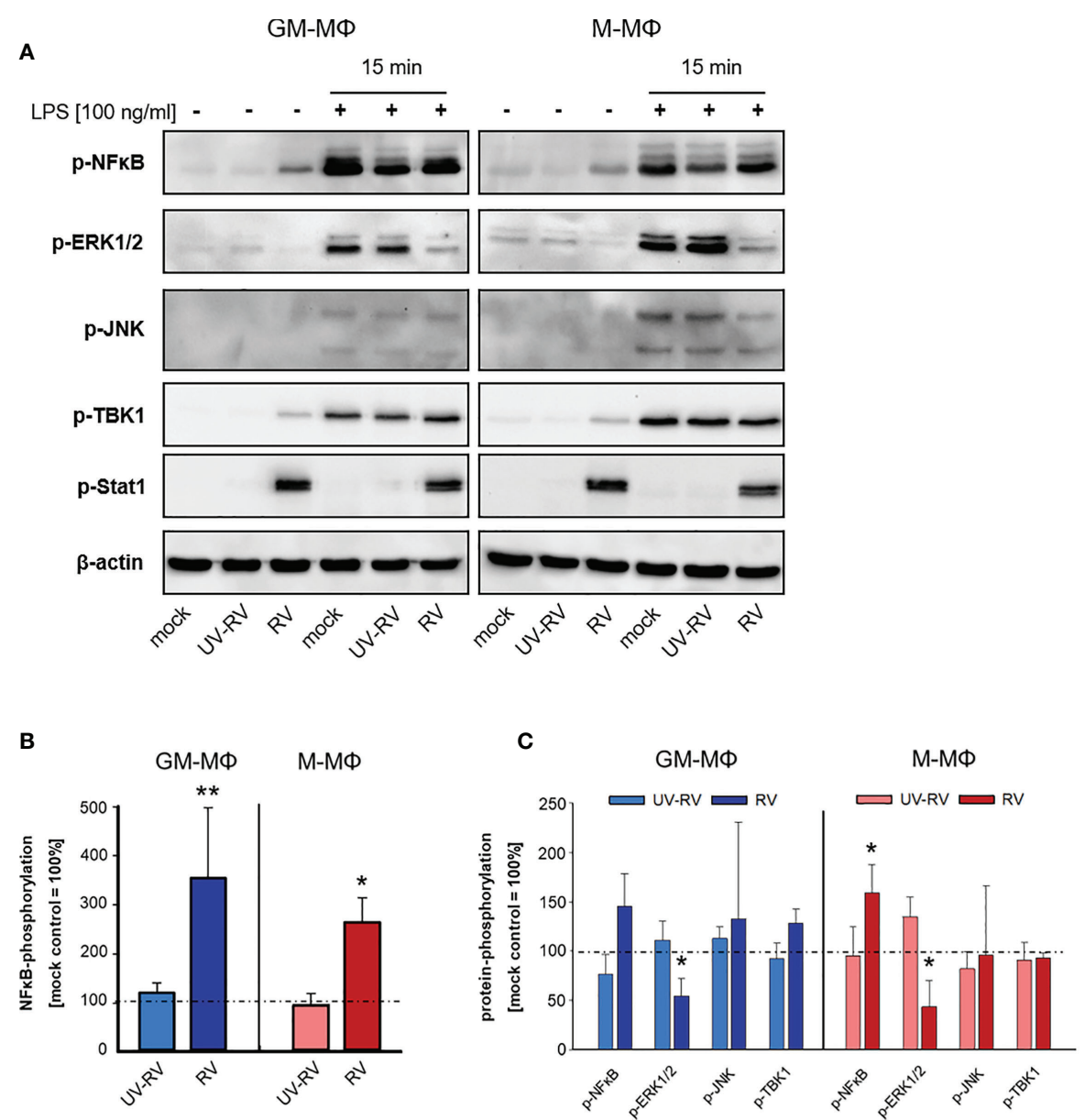

FIGURE 5 | LPS-induced signal transduction after infection with RV. (A) $24 \mathrm{~h}$ after incubation RV-, UV-RV- and mock-infected M $\Phi$ (5x10 $5 / m l)$ were incubated in the presence and absence of LPS (100 ng/ml). After 15 min cells were lysed using RIPA buffer and protein fractions were separated by SDS-PAGE and subjected to western blot analysis using Ab specific for the indicated proteins. One representative blot out of three is shown. Western blot bands of mock-, UV-RV- and RVinfected cells incubated without (B) and with LPS (100 ng/ml) $\mathbf{( C )}$ were quantified as relative intensities after normalization to the loading control $\beta$-actin. Data are presented as percent of optical density of the respective mock control (= 100\%) and as means \pm SD $(n=3)$. Statistical analysis was performed using the ANOVA test and significances were calculated to the mock control. ${ }^{*} p \leq 0.05,{ }^{* *} p \leq 0.01$.

involved in the host defense against infections (41). Due to its well-characterized effects on $M \Phi$ including the induction of the potent pro-inflammatory cytokine TNF- $\alpha$, this intensively studied compound is best suited to examine the effects of

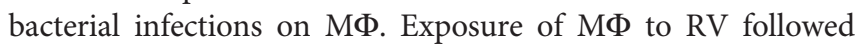
by washing 24 hours post-infection and subsequent incubation for $6 \mathrm{~h}$ resulted in a low IFN-response compared to amounts reached after virus infection at $24 \mathrm{hpi}$. This decline of the antiviral IFN-response over time of infection could contribute to the still unclear mode of persistence of reactivated $\mathrm{RV}$ vaccine strain in M2 MФ in PID patients (10). Moreover, the replication of RV in $M \Phi$ could support virus dissemination within the body, as RV was successfully isolated from mononuclear cells from synovial fluid as well as from peripheral blood (42). Such a mode of $\mathrm{M} \Phi$-assisted viral dissemination was described for several viruses including the cell-to-cell based transfer of measles virus from infected MФ to epithelial cells $(3,43)$.
Although the IFN- $\beta$ and $-\lambda 1$ protein concentrations drastically declined under these assay conditions, the mRNA levels remained elevated. Consistent with this finding, in vitro transcription/ translation reactions have shown, that viral capsid protein downregulates protein synthesis. The capsid protein interacts with poly(A) binding protein (PABP), which seems to interrupt the binding of PABP to the translation initiation complex (IF4F) (44).

Translational and transcriptional activity started again when LPS was added, indicating that RV primed the cells to react to the LPS-induced stimuli. A similar response was obtained when RV was substituted by IFN- $\beta$ supporting the presumption that IFN$\beta$ might be an important priming stimulus induced by RV. Either $\mathrm{RV}$ infection or low amounts of exogenously added IFN- $\beta$ (20 $\mathrm{pg} / \mathrm{ml}$ ) shown to be sufficient to induce phosphorylation of Stat1 a transcription factor important for production of ISGs. This indicates a role of IFN- $\beta$ in priming of $M \Phi$ for enhanced production of IFNs in response to other stimuli. 
un-infected MФ (0 h) / LPS challenge
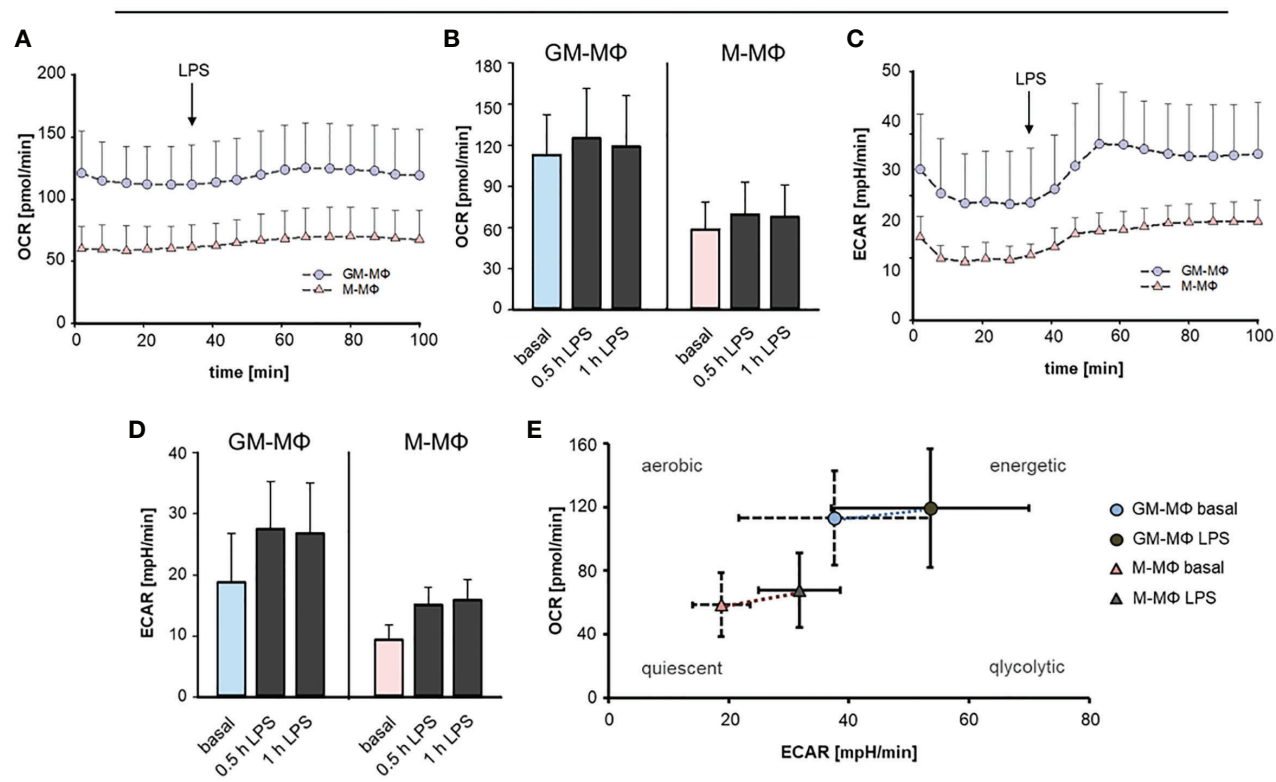

$24 \mathrm{~h}$ treated MФ / LPS challenge

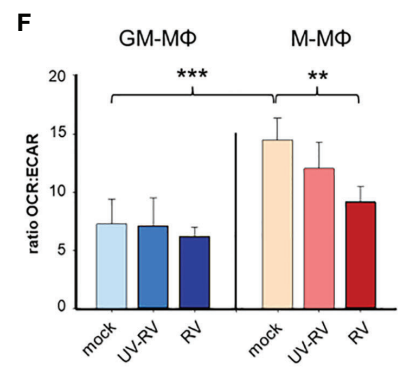

G

H
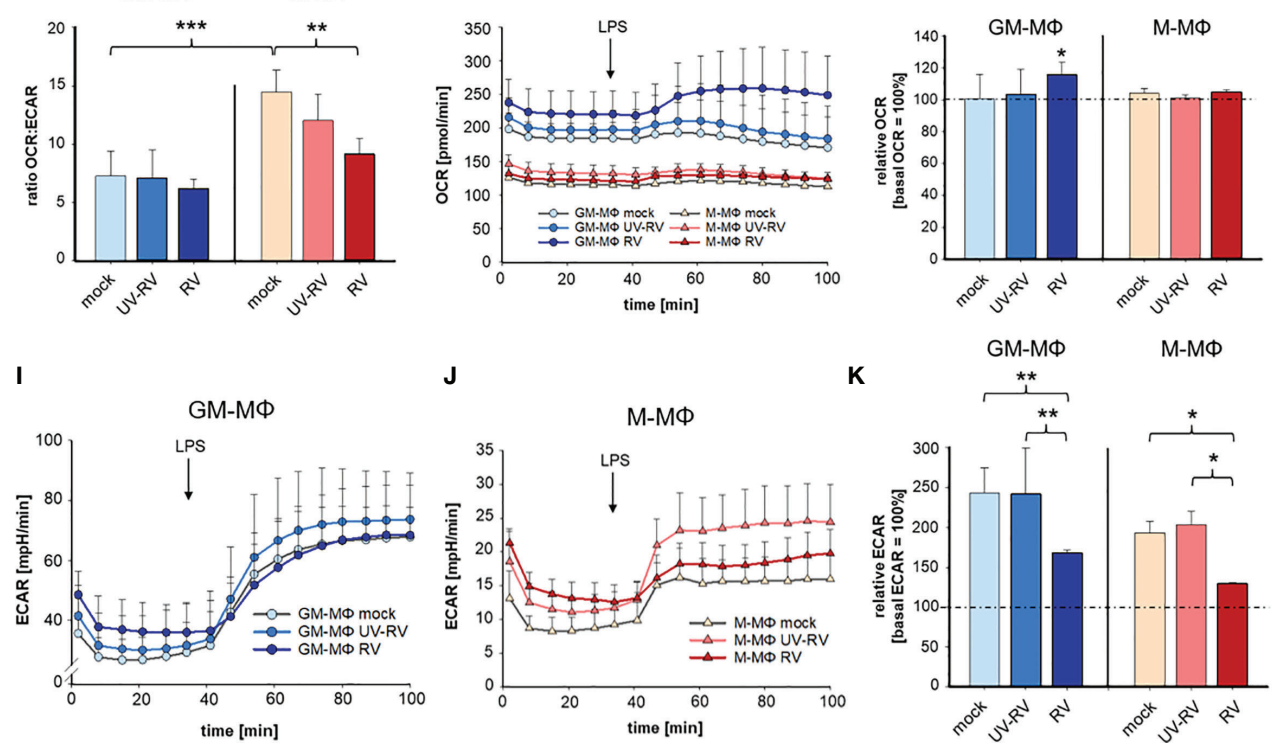

$\mathbf{J}$

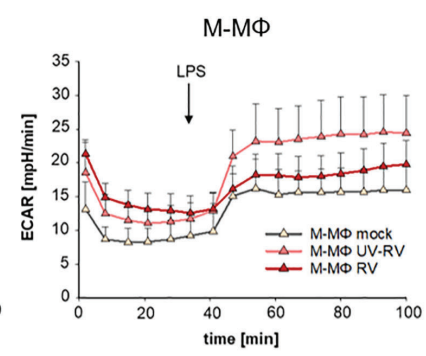

K

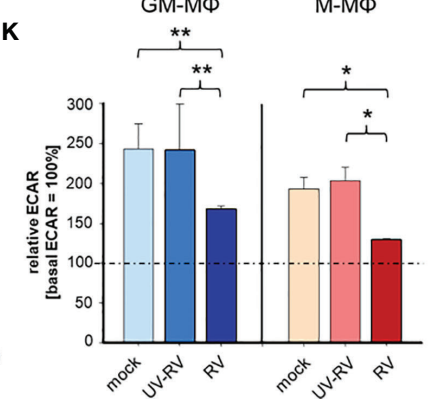

FIGURE 6 | LPS-induced metabolic response after infection with RV. Extracellular flux analysis was performed in an XFp analyser and metabolic activity in M $\Phi$ was measured as oxygen consumption rate (OCR) and extracellular acidification rate (ECAR). OCR and ECAR were measured at 16 measurement points every 6 min.

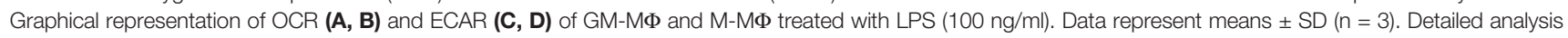

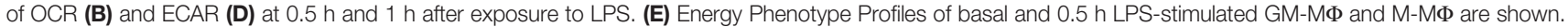
Data represent means \pm SD $(n=3)$. (F-K) At 24 hpi mock-, UV-RV- and RV-infected GM- and M-M $\Phi$ were measured in extracellular flux analysis. (F) The ratio of the OCR to ECAR (OCR basa/ $_{\text {ECAR basal }}$ ) at basal conditions (before application of LPS) was calculated as means $\pm S D(n=3)$. Statistical analysis was performed using

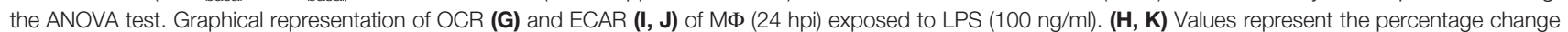
of OCR and ECAR 30 min after exposure to LPS relative to basal measurements (= 100\%). Statistical analysis for $(\mathbf{H}, \mathbf{K})$ was performed using the ANOVA test and significances were calculated to basal OCR or $\operatorname{ECAR}(=100 \%) .{ }^{*} p \leq 0.05,{ }^{* *} p \leq 0.01,{ }^{* \star} p \leq 0.001$. 

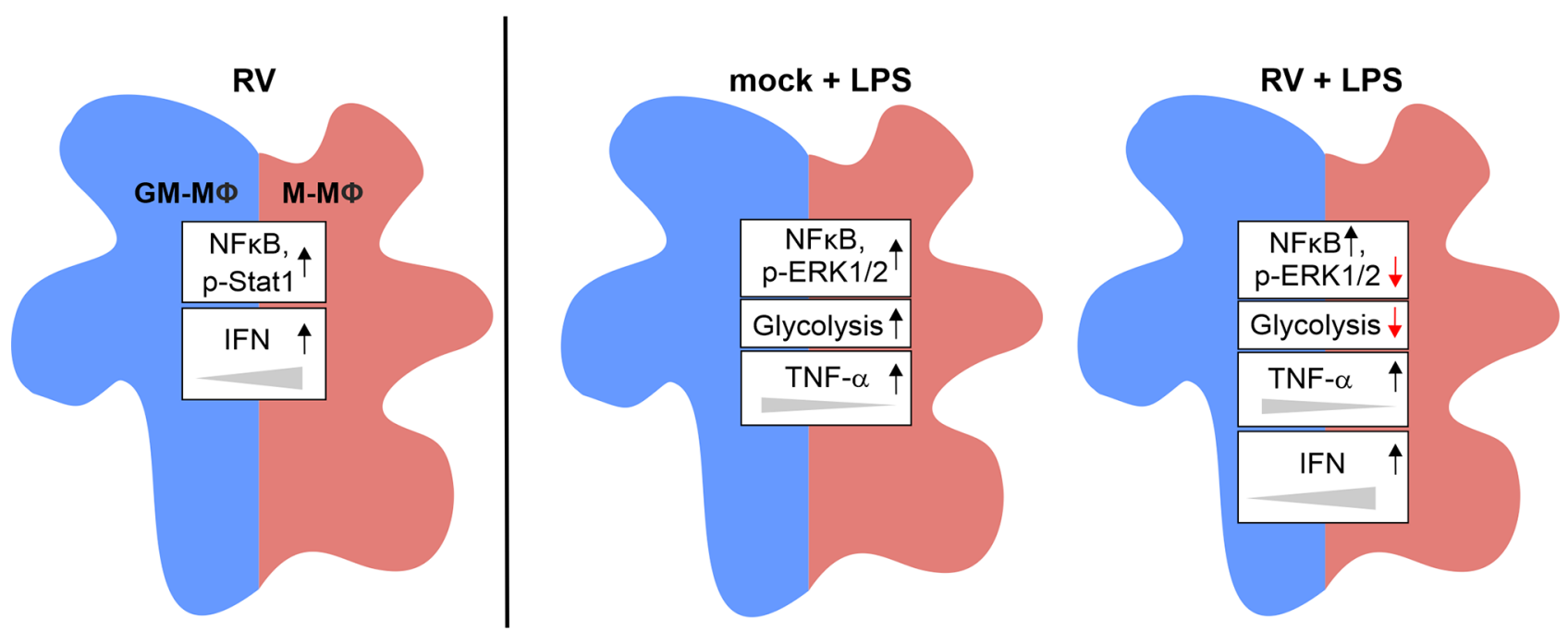

FIGURE 7 | Graphical summary of the data presented. Exposure of GM- and M-MФ to RV for 24 h results in altered metabolic and signal transduction pathways and in increased IFN levels preferentially in M-MФ. Co-stimulation with LPS revealed differential responses in metabolic events, signal transduction mechanisms and cytokine response between $\mathrm{RV}$ and mock infection.

It has been sheen that priming mechanisms seem to be of great importance (27), when the amounts of IFNs are limiting and augmentation of IFN-signalling is required to meet viral and bacterial challenges $(45,46)$. At present it is unclear to what extent the presence of the virus within the two $M \Phi$ subsets contributes to the LPS-induced renewed increase in IFN-signalling.

The here used stimulus LPS added $24 \mathrm{~h}$ after incubation in the absence of RV does not induce IFN-production. It initiates TRIFdependent phosphorylation of TBK1, which would be consistent with an enhanced IFN-production but the missing phosphorylation of Stat1 does not support this assumption. The full activation of the TRIF-TBK1-IRF3/7-Stat1 pathway and augmentation of IFN-production requires RV.

To our surprise we found ERK1/2, a member of the MAPkinase (MAPK) family, to be downregulated after pre-infection with RV. ERK1/2 which becomes activated not only by engagement of LPS signalling (47) as shown here but also in response to type I IFNs $(45,48)$, phosphorylates and thus activates Stat1. Stat1 in turn enhances either independently or together with $\mathrm{NFKB}$ and $\mathrm{AP}-1$ transcriptional activity and downstream ISG (interferon-stimulated gene) induction. As this enhancement is dependent on the activation of the kinases it is difficult to envisage how inactivation of ERK1/2 as described here, contributes to the noted increase in cytokine production especially after LPS challenge. For the RK13 kidney cell line, it was shown that RV infection led to increasing levels of phosphorylated ERK and that inhibition of Ras-Raf-MEK-ERK signalling resulted in reduced RV replication (49).

Unlike the here described RV-induced priming effect, infection of $M \Phi$ with human rhinovirus instead of RV has been reported to impair the cytokine response to LPS (50). Thus, the type of virus seems to be crucial for the outcome of a secondary bacterial stimulation and no predictions can be made.

In this study we also provide evidence that activation of GMand M-M $\Phi$ with either bacterial or viral stimuli not only results in functional but also in metabolic changes. Consistent with previous reports we found that exposure to LPS caused an increase in glycolysis $(51,52)$ a metabolic shift proven to be critical not only for enhanced production of pro-inflammatory cytokines, notably IL-1 $\beta$ (53) but also for other monocytic functions, such as processes involved in leucocyte adhesion cascades (54).

However, less well studied is the role of glycolysis in mediating macrophage/monocyte activation and function following viral infection. It has been shown that in $M \Phi$ cytosolic viral recognition by way of secondary IFN signalling results in upregulation of glycolysis in a PFKFB3 (6phosphofructo-2-kinase/fructose-2,6-biphosphatase 3) dependent manner (55). Engagement of this pathway supported the engulfment and removal of virus-infected cells thus providing evidence that glycolysis is closely related to antiviral activity in these immune cells (55). RV infection also resulted in a slight upregulation of glycolysis preferentially in $\mathrm{M}-\mathrm{M} \Phi$, however, it dampened glycolysis induced by challenge with LPS in both M $\Phi$ subsets. The contribution of the RVinduced IFN to the observed decrease in glycolysis needs to be addressed in further studies. Recently it was shown for murine bone marrow-derived M $\Phi$ that the application of IFN- $\beta$ restrains glycolysis (56).

Surprisingly despite a reduced glycolytic activity oxidative phosphorylation was not affected, indicating that glycolysis was not coupled to cellular respiration. Similar observations have been published previously (48) but inhibition of oxidative phosphorylation coupled with a corresponding increase in 
glycolysis has also been described (20). This metabolic reprogramming seems to be of great importance as the cells are faced with different functional demands.

In summary by investigating not only metabolic but also functional and signalling events in $М \Phi$ exposed to viral infection and bacterial stimulation in succession we here contribute to a field of great clinical importance. Our data add to the understanding of the still ill-defined involvement of MФ in prenatal and postnatal RV infection. Moreover, these immune cells could also be involved in the still undercharacterized mode of vertical transmission of RV during pregnancy. In the case of Zika virus transmission during pregnancy placental $M \Phi$ were shown to be permissive to Zika virus and maternal blood is the likely source of the infection of the placenta $(57,58)$. We found that human $M \Phi$ infected with RV to become more responsive to a bacterial stimulus, thus amplifying the cytokine response and inducing changes in metabolic reprogramming and in signal transduction mechanisms.

\section{DATA AVAILABILITY STATEMENT}

The raw data supporting the conclusions of this article will be made available by the authors, without undue reservation.

\section{REFERENCES}

1. Martinez FO, Gordon S. The M1 and M2 Paradigm of Macrophage Activation: Time for Reassessment. F1000Prime Rep (2014) 6:13. doi: $10.12703 /$ P6-13

2. Fleetwood AJ, Dinh H, Cook AD, Hertzog PJ, Hamilton JA. GM-CSF- and MCSF-Dependent Macrophage Phenotypes Display Differential Dependence on Type I Interferon Signaling. J leukocyte Biol (2009) 86:411-21. doi: 10.1189/ jlb.1108702

3. Nikitina E, Larionova I, Choinzonov E, Kzhyshkowska J. Monocytes and Macrophages as Viral Targets and Reservoirs. Int J Mol Sci (2018) 19:2821. doi: $10.3390 /$ ijms19092821

4. Labadie K, Larcher T, Joubert C, Mannioui A, Delache B, Brochard P, et al. Chikungunya Disease in Nonhuman Primates Involves Long-Term Viral Persistence in Macrophages. J Clin Invest (2010) 120:894-906. doi: 10.1172/ JCI40104

5. Stevenson EV, Collins-McMillen D, Kim JH, Cieply SJ, Bentz GL, Yurochko AD. HCMV Reprogramming of Infected Monocyte Survival and Differentiation: A Goldilocks Phenomenon. Viruses (2014) 6:782-807. doi: $10.3390 / v 6020782$

6. Le Douce V, Herbein G, Rohr O, Schwartz C. Molecular Mechanisms of HIV1 Persistence in the Monocyte-Macrophage Lineage. Retrovirology (2010) 7:32. doi: 10.1186/1742-4690-7-32

7. Parkman PD. Togaviruses: Rubella Virus. In: S Baron, editor. Medical Microbiology: Togaviruses: Rubella Virus. Galveston (TX): University of Texas Medical Branch at Galveston (1996).

8. van der Logt JT, van Loon AM, van der Veen J. Replication of Rubella Virus in Human Mononuclear Blood Cells. Infect Immun (1980) 27:309-14. doi: 10.1128/iai.27.2.309-314.1980

9. Lazar M, Perelygina L, Martines R, Greer P, Paddock CD, Peltecu G, et al. Immunolocalization and Distribution of Rubella Antigen in Fatal Congenital Rubella Syndrome. EBioMedicine (2016) 3:86-92. doi: 10.1016/j.ebiom.2015.11.050

10. Perelygina L, Plotkin S, Russo P, Hautala T, Bonilla F, Ochs HD, et al. Rubella Persistence in Epidermal Keratinocytes and Granuloma M2 Macrophages in Patients With Primary Immunodeficiencies. J Allergy Clin Immunol (2016) 138:1436-9.e11. doi: 10.1016/j.jaci.2016.06.030

11. Zobel S, Lorenz M, Frascaroli G, Böhnke J, Bilz NC, Stanifer ML, et al. Rubella Virus Strain-Associated Differences in the Induction of Oxidative Stress Are

\section{ETHICS STATEMENT}

The studies involving human participants were reviewed and approved by Medical Faculty, Leipzig University, Liebigstraße 18, 04103 Leipzig. The patients/participants provided their written informed consent to participate in this study.

\section{AUTHOR CONTRIBUTIONS}

SH, CC, AG, and ES contributed to conceptualisation. ES, AG, CC, and LP carried out the experiments. ES, SH, and CC wrote the first draft of the manuscript. SH, CC, AG, and UK reviewed and edited the draft of the manuscript. All authors contributed to final manuscript revision, read and approved the submitted version.

\section{ACKNOWLEDGMENTS}

The authors acknowledge B. Weißbrich (University of Wuerzburg, Germany) for provision of Wb-12 strain. We acknowledge support from Leipzig University for Open Access Publishing.

Independent of Their Interferon Activation. Viruses (2018) 10:540. doi: $10.3390 / \mathrm{v} 10100540$

12. Schilling E, Weiss R, Grahnert A, Bitar M, Sack U, Hauschildt S. Molecular Mechanism of LPS-Induced TNF- $\alpha$ Biosynthesis in Polarized Human Macrophages. Mol Immunol (2018) 93:206-15. doi: 10.1016/j.molimm.2017.11.026

13. Grahnert A, Weiss R, Schilling E, Stanslowsky N, Sack U, Hauschildt S. CD14 Counterregulates Lipopolysacharide-Induced Tumor Necrosis Factor- $\alpha$ Production in a Macrophage Subset. J Innate Immun (2019) 11:359-74. doi: $10.1159 / 000495528$

14. Kräter M, Sapudom J, Bilz NC, Pompe T, Guck J, Claus C. Alterations in Cell Mechanics by Actin Cytoskeletal Changes Correlate With Strain-Specific Rubella Virus Phenotypes for Cell Migration and Induction of Apoptosis. Cells (2018) 7(9):136. doi: 10.3390/cells7090136

15. Claus C, Bergs S, Emmrich NC, Hübschen JM, Mankertz A, Liebert UG. A Sensitive One-Step TaqMan Amplification Approach for Detection of Rubella Virus Clade I and II Genotypes in Clinical Samples. Arch Virol (2017) 162:477-86. doi: 10.1007/s00705-016-3131-1

16. Ishii T, Wallace AM, Zhang X, Gosselink J, Abboud RT, English JC, et al. Stability of Housekeeping Genes in Alveolar Macrophages From COPD Patients. Eur Respir J (2006) 27:300-6. doi: 10.1183/09031936.06.00090405

17. Li P, Wong JJ-Y, Sum C, Sin W-X, Ng K-Q, Koh MB, et al. IRF8 and IRF3 Cooperatively Regulate Rapid Interferon- $\beta$ Induction in Human Blood Monocytes. Blood (2011) 117:2847-54. doi: 10.1182/blood-2010-07-294272

18. Bender S, Reuter A, Eberle F, Einhorn E, Binder M, Bartenschlager R. Activation of Type I and III Interferon Response by Mitochondrial and Peroxisomal MAVS and Inhibition by Hepatitis C Virus. PloS Pathog (2015) 11:e1005264. doi: 10.1371/journal.ppat.1005264

19. Read SA, Wijaya R, Ramezani-Moghadam M, Tay E, Schibeci S, Liddle C, et al. Macrophage Coordination of the Interferon Lambda Immune Response. Front Immunol (2019) 10:2674. doi: 10.3389/fimmu.2019.02674

20. Grahnert A, Richter S, Siegert F, Berndt A, Hauschildt S. The Orthologue of the "Acatalytic" Mammalian ART4 in Chicken Is an Arginine-Specific Mono-ADPRibosyltransferase. BMC Mol Biol (2008) 9:86. doi: 10.1186/1471-2199-9-86

21. Verreck FA, de Boer T, Langenberg DM, van der Zanden L, Ottenhoff TH. Phenotypic and Functional Profiling of Human Proinflammatory Type-1 and Anti-Inflammatory Type-2 Macrophages in Response to Microbial Antigens and IFN-Gamma- and CD40L-Mediated Costimulation. J Leukocyte Biol (2006) 79:285-93. doi: 10.1189/jlb.0105015 
22. Lee AJ, Chen B, Chew MV, Barra NG, Shenouda MM, Nham T, et al. Inflammatory Monocytes Require Type I Interferon Receptor Signaling to Activate NK Cells via IL-18 During a Mucosal Viral Infection. J Exp Med (2017) 214:1153-67. doi: 10.1084/jem.20160880

23. Randall RE, Goodbourn S. Interferons and Viruses: An Interplay Between Induction, Signalling, Antiviral Responses and Virus Countermeasures. J Gen Virol (2008) 89:1-47. doi: 10.1099/vir.0.83391-0

24. Fitzgerald KA, McWhirter SM, Faia KL, Rowe DC, Latz E, Golenbock DT, et al. IKKepsilon and TBK1 Are Essential Components of the IRF3 Signaling Pathway. Nat Immunol (2003) 4:491-6. doi: 10.1038/ni921

25. Kawai T, Akira S. The Role of Pattern-Recognition Receptors in Innate Immunity: Update on Toll-Like Receptors. Nat Immunol (2010) 11:373-84. doi: $10.1038 /$ ni. 1863

26. Sato M, Hata N, Asagiri M, Nakaya T, Taniguchi T, Tanaka N. Positive Feedback Regulation of Type I IFN Genes by the IFN-Inducible Transcription Factor IRF-7. FEBS Lett (1998) 441:106-10. doi: 10.1016/s0014-5793(98) 01514-2

27. Taniguchi $T$, Takaoka $A$. The Interferon- $\alpha / \beta$ System in Antiviral Responses: A Multimodal Machinery of Gene Regulation by the IRF Family of Transcription Factors. Curr Opin Immunol (2002) 14:111-6. doi: 10.1016/ s0952-7915(01)00305-3

28. Malmgaard L. Induction and Regulation of IFNs During Viral Infections. J Interferon Cytokine Res (2004) 24:439-54. doi: 10.1089/1079990041689665

29. Akira S, Takeda K. Toll-Like Receptor Signalling. Nat Rev Immunol (2004) 4:499-511. doi: 10.1038/nri1391

30. Sharma S, tenOever BR, Grandvaux N, Zhou G-P, Lin R, Hiscott J. Triggering the Interferon Antiviral Response Through an IKK-Related Pathway. Science (2003) 300:1148-51. doi: 10.1126/science.1081315

31. Hemmi H, Takeuchi O, Sato S, Yamamoto M, Kaisho T, Sanjo H, et al. The Roles of Two IkappaB Kinase-Related Kinases in Lipopolysaccharide and Double Stranded RNA Signaling and Viral Infection. J Exp Med (2004) 199:1641-50. doi: 10.1084/jem.20040520

32. Li Q, Verma IM. NF-kappaB Regulation in the Immune System. Nat Rev Immunol (2002) 2:725-34. doi: 10.1038/nri910

33. Lenardo MJ, Fan C-M, Maniatis T, Baltimore D. The Involvement of NF- $\kappa b$ in $\beta$-Interferon Gene Regulation Reveals its Role as Widely Inducible Mediator of Signal Transduction. Cell (1989) 57:287-94. doi: 10.1016/0092-8674(89) 90966-5

34. Wathelet MG, Lin CH, Parekh BS, Ronco LV, Howley PM, Maniatis T. Virus Infection Induces the Assembly of Coordinately Activated Transcription Factors on the IFN- $\beta$ Enhancer In Vivo. Mol Cell (1998) 1:507-18. doi: 10.1016/s1097-2765(00)80051-9

35. Bilz NC, Jahn K, Lorenz M, Lüdtke A, Hübschen JM, Geyer H, et al. Rubella Viruses Shift Cellular Bioenergetics to a More Oxidative and Glycolytic Phenotype With a Strain-Specific Requirement for Glutamine. J Virol (2018) 92:13. doi: 10.1128/JVI.00934-18

36. Uzé G, Monneron D. IL-28 and IL-29: Newcomers to the Interferon Family. Biochimie (2007) 89:729-34. doi: 10.1016/j.biochi.2007.01.008

37. Li X, Leung S, Qureshi S, Darnell JE, Stark GR. Formation of STAT1-STAT2 Heterodimers and Their Role in the Activation of IRF-1 Gene Transcription by Interferon-Alpha. J Biol Chem (1996) 271:5790-4. doi: 10.1074/ jbc. 271.10 .5790

38. Darnell JE, Kerr IM, Stark GR. Jak-STAT Pathways and Transcriptional Activation in Response to IFNs and Other Extracellular Signaling Proteins. Science (1994) 264:1415-21. doi: 10.1126/science.8197455

39. Kotenko SV, Gallagher G, Baurin VV, Lewis-Antes A, Shen M, Shah NK, et al. IFN-Lambdas Mediate Antiviral Protection Through a Distinct Class II Cytokine Receptor Complex. Nat Immunol (2003) 4:69-77. doi: 10.1038/ ni875

40. Sheppard P, Kindsvogel W, Xu W, Henderson K, Schlutsmeyer S, Whitmore TE, et al. IL-28, IL-29 and Their Class II Cytokine Receptor IL-28r. Nat Immunol (2003) 4:63-8. doi: 10.1038/ni873

41. Rietschel ET, Brade L, Lindner B, Zahringer U. Biochemistry of Lipopolysaccharides. In: Morrison DC, Ryan JL, editor. Bacterial Endotoxic Lipopolysaccharides. Vol. 1. Boca Raton, Fla: CRC Press (1992). p.3-41.

42. Chantler JK, Tingle AJ, Petty RE. Persistent Rubella Virus Infection Associated With Chronic Arthritis in Children. N Engl J Med (1985) 313:1117-23. doi: 10.1056/NEJM198510313131803
43. Singh BK, Li N, Mark AC, Mateo M, Cattaneo R, Sinn PL. Cell-To-Cell Contact and Nectin-4 Govern Spread of Measles Virus From Primary Human Myeloid Cells to Primary Human Airway Epithelial Cells. J Virol (2016) 90:6808-17. doi: 10.1128/JVI.00266-16

44. Ilkow CS, Mancinelli V, Beatch MD, Hobman TC. Rubella Virus Capsid Protein Interacts With Poly(a)-Binding Protein and Inhibits Translation. J Virol (2008) 82:4284-94. doi: 10.1128/JVI.02732-07

45. van Boxel-Dezaire AH, Rani MR, Stark GR. Complex Modulation of Cell Type-Specific Signaling in Response to Type I Interferons. Immunity (2006) 25:361-72. doi: 10.1016/j.immuni.2006.08.014

46. Yarilina A, Park-Min K-H, Antoniv T, Hu X, Ivashkiv LB. TNF Activates an IRF1-Dependent Autocrine Loop Leading to Sustained Expression of Chemokines and STAT1-Dependent Type I Interferon-Response Genes. Nat Immunol (2008) 9:378-87. doi: 10.1038/ni1576

47. Stark GR, Darnell JE. The JAK-STAT Pathway at Twenty. Immunity (2012) 36:503-14. doi: 10.1016/j.immuni.2012.03.013

48. Kim M-O, Si Q, Zhou JN, Pestell RG, Brosnan CF, Locker J, et al. InterferonBeta Activates Multiple Signaling Cascades in Primary Human Microglia. J Neurochem (2002) 81:1361-71. doi: 10.1046/j.1471-4159.2002.00949.x

49. Cooray S, Jin L, Best JM. The Involvement of Survival Signaling Pathways in Rubella-Virus Induced Apoptosis. Virol J (2005) 2:1. doi: 10.1186/1743-422X-2-1

50. Jubrail J, Africano-Gomez K, Herit F, Baturcam E, Mayer G, Cunoosamy DM, et al. HRV16 Impairs Macrophages Cytokine Response to a Secondary Bacterial Trigger. Front Immunol (2018) 9:2908. doi: 10.3389/fimmu.2018.02908

51. Galván-Peña S, O’Neill LA. Metabolic Reprograming in Macrophage Polarization. Front Immunol (2014) 5:420. doi: 10.3389/fimmu.2014.00420

52. Rodríguez-Prados J-C, Través PG, Cuenca J, Rico D, Aragonés J, Martín-Sanz P, et al. Substrate Fate in Activated Macrophages: A Comparison Between Innate, Classic, and Alternative Activation. J Immunol (2010) 185:605-14. doi: 10.4049/jimmunol.0901698

53. Tannahill GM, Curtis AM, Adamik J, Palsson-McDermott EM, McGettrick AF, Goel G, et al. Succinate Is an Inflammatory Signal That Induces IL-1 $\beta$ Through HIF-1 $\alpha$. Nature (2013) 496:238-42. doi: 10.1038/nature11986

54. Lee MK, Al-Sharea A, Shihata WA, Bertuzzo Veiga C, Cooney OD, Fleetwood AJ, et al. Glycolysis Is Required for LPS-Induced Activation and Adhesion of Human CD14+CD16- Monocytes. Front Immunol (2019) 10:2054. doi: 10.3389/fimmu.2019.02054

55. Jiang H, Shi H, Sun M, Wang Y, Meng Q, Guo P, et al. PFKFB3-Driven Macrophage Glycolytic Metabolism Is a Crucial Component of Innate Antiviral Defense. J Immunol (2016) 197:2880-90. doi: 10.4049/jimmunol.1600474

56. Olson GS, Murray TA, Jahn AN, Mai D, Diercks AH, Gold ES, et al. Type I Interferon Decreases Macrophage Energy Metabolism During Mycobacterial Infection. Cell Rep (2021) 35:109195. doi: 10.1016/j.celrep.2021.109195

57. Boeuf P, Drummer HE, Richards JS, Scoullar MJ, Beeson JG. The Global Threat of Zika Virus to Pregnancy: Epidemiology, Clinical Perspectives, Mechanisms, and Impact. BMC Med (2016) 14:112. doi: 10.1186/s12916016-0660-0

58. Quicke KM, Bowen JR, Johnson EL, McDonald CE, Ma H, O’Neal JT, et al. Zika Virus Infects Human Placental Macrophages. Cell Host Microbe (2016) 20:83-90. doi: 10.1016/j.chom.2016.05.015

Conflict of Interest: The authors declare that the research was conducted in the absence of any commercial or financial relationships that could be construed as a potential conflict of interest.

Publisher's Note: All claims expressed in this article are solely those of the authors and do not necessarily represent those of their affiliated organizations, or those of the publisher, the editors and the reviewers. Any product that may be evaluated in this article, or claim that may be made by its manufacturer, is not guaranteed or endorsed by the publisher.

Copyright (C) 2021 Schilling, Grahnert, Pfeiffer, Koehl, Claus and Hauschildt. This is an open-access article distributed under the terms of the Creative Commons Attribution License (CC BY). The use, distribution or reproduction in other forums is permitted, provided the original author(s) and the copyright owner(s) are credited and that the original publication in this journal is cited, in accordance with accepted academic practice. No use, distribution or reproduction is permitted which does not comply with these terms. 